
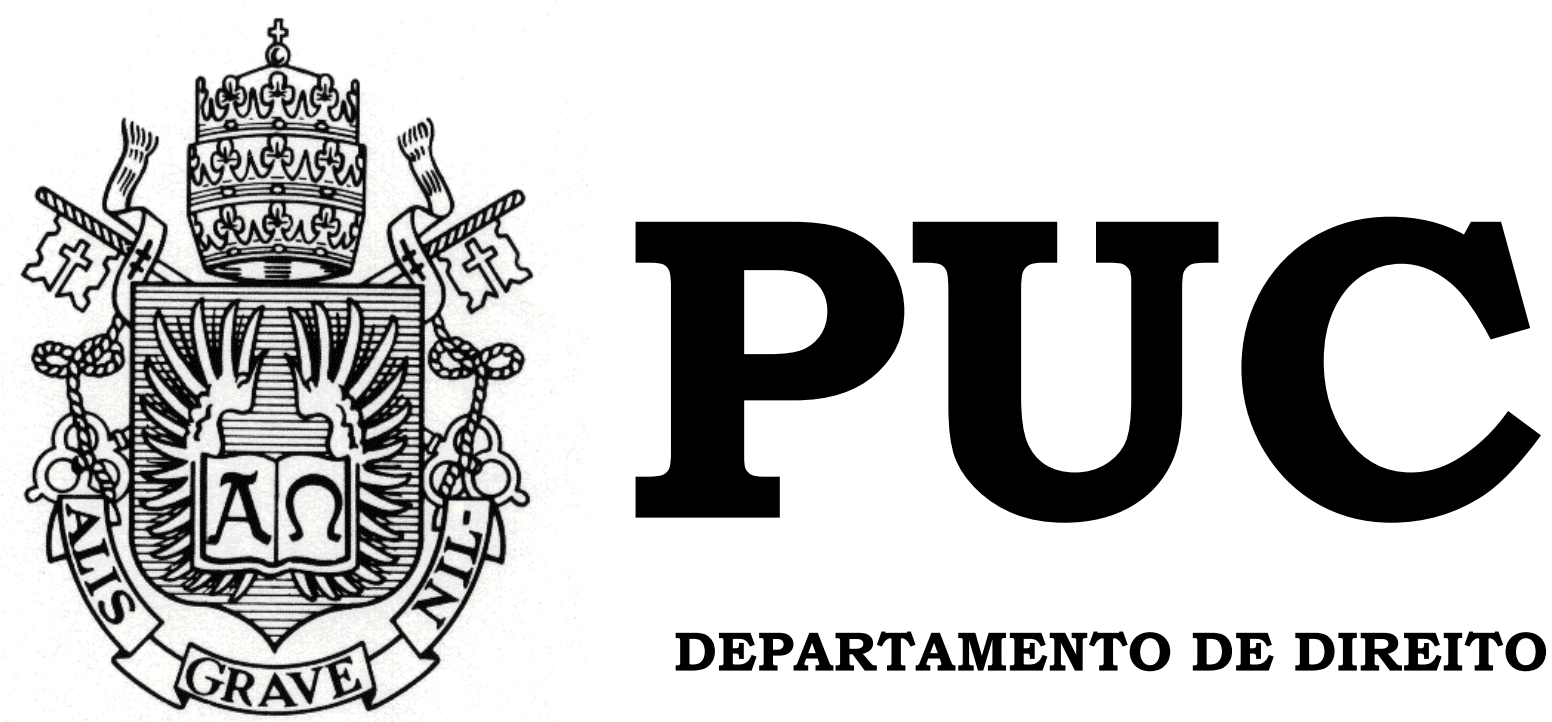

DEPARTAMENTO DE DIREITO

\title{
INITIAL COIN OFFERING: ANÁLISE SOBRE A POSSÍVEL CONFIGURAÇÃO COMO UMA OFERTA DE VALORES MOBILIÁRIOS
}

Por

JULIA BERNARDES CUNHA

ORIENTADOR: Julian Fonseca Peña Chediak

2018.2

PONTIFÍCIA UNIVERSIDADE CATÓLICA DO RIO DE JANEIRO

RUA MARQUÊS DE SÃO VICENTE, 225 - CEP 22451-900

RIO DE JANEIRO - BRASIL 


\section{INITIAL COIN OFFERING: \\ ANÁLISE SOBRE A POSSÍVEL \\ CONFIGURAÇÃO COMO UMA \\ OFERTA DE VALORES \\ MOBILIÁRIOS}

por

JULIA BERNARDES CUNHA

Monografia apresentada ao

Departamento de Direito da Pontifícia Universidade Católica do Rio de Janeiro (PUC-Rio) como requisito parcial para obtenção do título de Bacharel em Direito.

Orientador: Julian Fonseca Peña Chediak 


\section{AGRADECIMENTOS}

"Obrigado a todas as pessoas que contribuíram para meu sucesso e para meu crescimento como pessoa. Sou o resultado da confiança e da força de cada um de vocês"

Augusto Branco

Em primeiro lugar, como não poderia ser diferente, gostaria de agradecer aos meus pais. É incrível ver como vocês criaram suas filhas para o mundo e sempre nos incentivam a ir mais longe. Obrigada por serem exemplos de cidadãos, profissionais, amigos, e o mais importante, os melhores pais que eu poderia desejar. Às minhas duas irmãs, Letícia e Sofia, tenham a certeza que crescer ao lado de vocês é o meu maior privilégio. Sem eles, não há a menor dúvida que essa trajetória não seria possível.

Aos meus amigos da faculdade, em especial, minha tão querida turma HB. Hoje tenho a certeza que "os amigos da faculdade são para vida toda". Obrigado por serem tanto e saibam que nossa amizade vai muito além do pilotis.

À equipe de Mercado de Capitais do Stocche Forbes (em especial, Ingrid, Analu, Edu, Felipe, Hugo, Pedrinho e Ju), fica aqui meu agradecimento especial por toda paciência e dedicação. Vocês são parte essencial no meu desenvolvimento profissional. Não é por menos que somos a "melhor equipe do mundo".

Ao meu orientador, Julian Chediak, deixo meu agradecimento pela paciência e pela orientação durante esta reta final. No mais, meu agradecimento a todo corpo docente do Departamento de Direito da Puc-Rio, vocês são parte essencial na nossa formação.

Voar para longe da minha cidade natal e me formar em uma grande universidade era um sonho que hoje conquistei. Desta forma, meu agradecimento a todos aqueles que tornaram isso possível. 


\section{RESUMO}

CUNHA, Julia Bernardes. Initial Coin Offering: Análise sobre a Possível Configuração como uma Oferta de Valores Mobiliários. Rio de Janeiro: 2018: p. 69. Monografia de final de curso. Departamento de Direito da Pontifícia Universidade Católica do Rio de Janeiro - PUC-Rio.

O presente trabalho pretende analisar as questões jurídicas de um initial coin offering à luz da atual regulamentação brasileira. Nele, serão examinados a natureza jurídica das criptomoedas, a definição de valor mobiliário e o procedimento do initial coin offering. A partir desta exposição, serão estudados os diferentes tokens distribuídos nessas ofertas para a posterior análise de sua possível configuração como oferta de valores mobiliários e uma breve comparação com ofertas iniciais de ações e o equity crowdfunding. Por fim, o atual entendimento dos principais países do mundo será abordado buscando o questionamento de possíveis alterações na regulamentação do mercado de capitais brasileiro visando adaptá-la aos initial coin offerings.

Palavras-Chave: Criptomoedas. Initial Coin Offering. Valores Mobiliários. IPO. Crowdfunding. 


\section{SUMÁRIO}

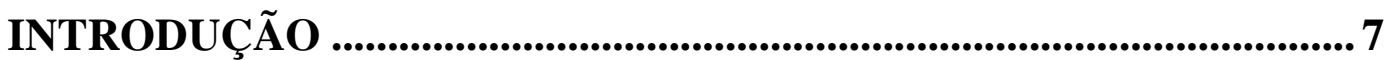

CAPÍTULO 1 - UMA ANÁLISE DAS CRIPTOMOEDAS ......................9

1.1. Sistema Monetário: Do escambo à Criptomoeda................................... 9

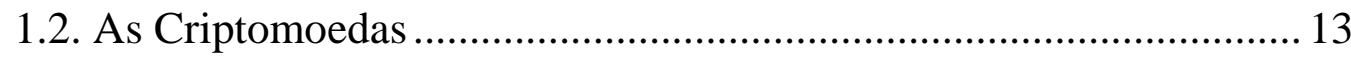

1.3. A Natureza Jurídica das Criptomoedas .............................................. 14

a) Moedas Fiduciárias .............................................................. 15

b) Moedas Digitais ................................................................. 16

c) A Natureza Híbrida das Criptomoedas ................................ 17

CAPÍTULO 2 - OS VALORES MOBILIÁRIOS ....................................... 19

2.1. A evolução do conceito de securities no direito norte-americano e o

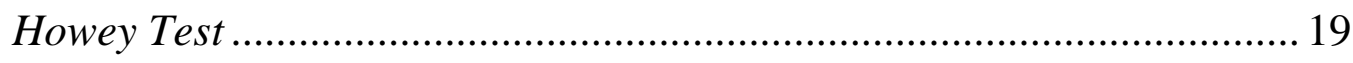

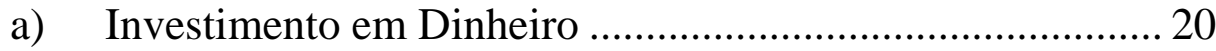

b) Empreendimento Comum ................................................... 21

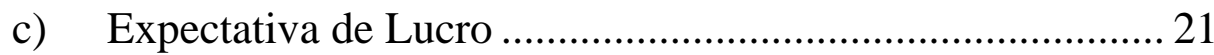

d) Desempenho exclusivo de Terceiros …………………........ 21

2.2. Os Valores Mobiliários no Direito Brasileiro ……………………...... 22

2.3. As criptomoedas como títulos ou contratos de investimento coletivo

CAPÍTULO 3 - O CONCEITO DO INITIAL COIN OFFERING...... 26

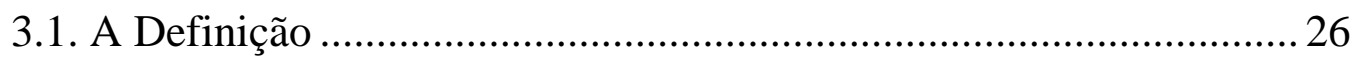

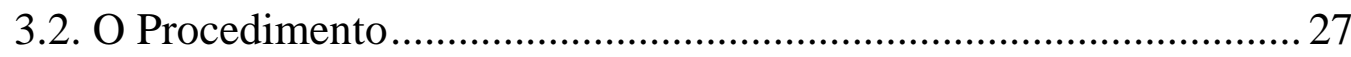

3.3. O conceito e as características dos tokens .......................................... 28

3.4. Os Utility Tokens e o Inital Coin Offering ………………………..... 30

a) O Caso Munchee Inc. ............................................................. 33

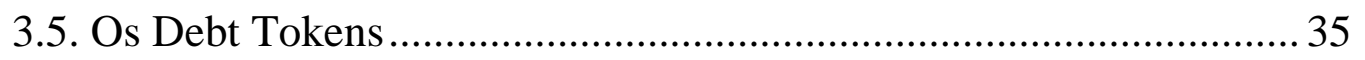

CAPÍTULO 4 -OS INITIAL COIN OFFERINGS E A ATUAL REGULAMENTAÇÃO DO BRASIL .................................................36

4.1. Equity Tokens e os Initial Coin Offerings ......................................... 36 
a) Oferta Irregular de Valores Mobiliários - Análise da oferta HashBrasil e Hashcoin Brasil..................................................... 37

4.2. Initial Coin Offering (ICO) vs. Initial Public Offering (IPO) .......... 39

a) Oferta Pública com Esforços Restritos (Instrução CVM n 476) 40

b) Oferta Pública de Valores Mobiliários (Instrução CVM nº 400) 42

c) A Inevitável Comparação 43

d) Uma Possível solução para a realização de ICOs via Instrução CVM n ${ }^{\circ} 400$. 48

4.3. Initial Coin Offering (ICO) vs. Crowdfunding .............................. 49

CAPÍTULO 5 - OS INITIAL COIN OFFERINGS NAS DEMAIS JURISDIÇÕES ................................................................................... 54

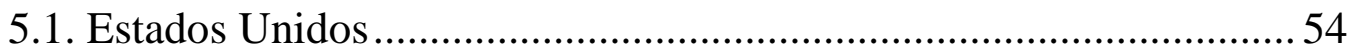

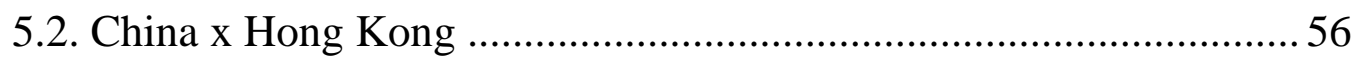

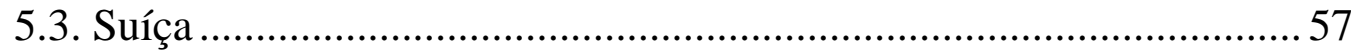

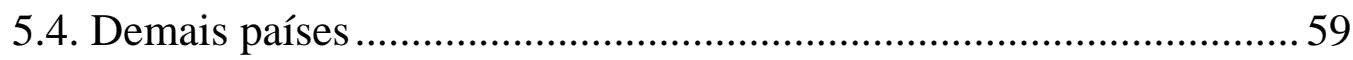

CONCLUSÃ O.....................................................................................61 61

REFERÊNCIAS BIBLIOGRÁFICAS ........................................... 63 


\section{LISTA DE ABREVIAÇÕES}

Art. - Artigo

BACEN - Banco Central do Brasil

BOMESP - Bolsa de Moedas Digitais Empresariais de São Paulo

CMN - Conselho Monetário Nacional

CVM - Comissão de Valores Mobiliários

ICO - Initial Coin Offering

IPO - Oferta Inicial de Ações

PFE - Procuradoria Federal Especializada

SEC - Securities and Exchange Commission

SRE - Superintendência de Registros de Valores Mobiliários. 


\section{INTRODUÇÃO}

Do escambo, a origem da moeda, ao subsequente desenvolvimento da intermediação financeira, perpassando pelas transformações econômicas e tecnológicas enfrentadas pela sociedade nos últimos anos, chegamos às chamadas "criptomoedas". Esta nova forma de pagamento, baseada em um bem digital, do qual o valor é resultado da confiança dos usuários no sistema, surge como um desafio ao legislador brasileiro.

Com o desenvolvimento das criptomoedas, surge também uma nova forma de captação de recursos, as chamadas Initial Coin Offerings. Por meio destas, empresas e start-ups conseguem levantar fundos a partir da emissão de ativos virtuais, também conhecidos como tokens ou coins, junto ao público investidor.

Neste contexto, em meio a discussões sobre a necessidade de regulamentação dos Initial Coin Offerings, a presente monografia propõe o estudo desta nova forma de financiamento, buscando a análise da natureza jurídica dos tokens distribuídos, a fim de explorar possíveis comparações com ofertas de valores mobiliários já regulamentadas.

Para tanto, será feita, no capítulo 1, uma breve retomada histórica sobre o sistema monetário, necessária para evidenciar sua constante transformação decorrente das atualizações tecnológicas da sociedade. Com isso, espera-se identificar os motivos que levaram a criação das criptomoedas, bem como uma definição sobre essa nova forma de pagamento. Após essa análise, ver-se-á as principais discussões sobre a natureza jurídica das criptomoedas, buscando analisar suas possíveis consequências jurídicas.

O capítulo 2 busca apresentar o conceito de valores mobiliários, com ênfase na origem do Howey Test. Após essa breve exposição, o capítulo propõe uma análise das criptomoedas como títulos ou contratos de investimento coletivo, nos termos do inciso IX do art. $2^{\circ}$ da Lei 6.385 . 
Por sua vez, o capítulo 3 funciona como um preâmbulo necessário para analisar o procedimento do Initial Coin Offering e os diferentes tokens que são distribuídos nessas ofertas. Nesse item, com base na análise de casos concretos, será exposto como as ofertas de utility tokens e debt tokens devem ser classificadas.

A possível configuração dos Initial Coin Offerings como ofertas de valores mobiliários será analisada no capítulo 4 , em conjunto com a exposição de casos já analisados pela CVM. Em um segundo momento, a proposta do capítulo é apresentar as Ofertas Iniciais de Ações e o Equity Crowdfunding, ambas formas de captação de recursos já regulamentados pela CVM, buscando compará-las com o Initial Coin Offering.

Por fim, o capítulo 5 propõe uma breve exposição do entendimento de diversos países sobre o tema, que varia entre proibições até diretrizes que buscam fomentar essa nova forma de investimento.

Como se verá, o Initial Coin Offering apresenta características únicas que acarretam na necessidade de uma nova regulamentação capaz de conferir a segurança necessária aos investidores. 


\section{CAPÍTULO 1 - UMA ANÁLISE DAS CRIPTOMOEDAS}

Para a análise jurídica do ICO proposta no presente trabalho, faz-se necessária uma breve contextualização histórica do surgimento da moeda à criação das criptomoedas. Tal contextualização é de suma importância para a compreensão das principais características das criptomoedas, bem como sua importância para o mercado atual.

\subsection{Sistema Monetário: Do escambo à Criptomoeda}

Do escambo às criptomoedas, a sociedade sofreu transformações econômicas e sociais que demandaram alterações na forma pela qual o fluxo monetário transitava entre os agentes. Se outrora a troca direta de serviços ou mercadorias, sem qualquer intervenção de terceiros delineava a economia, $a$ posteriori, a dificuldade de especialização e divisão do trabalho, por exemplo, passa a evidenciar a insustentabilidade deste modelo, abrindo frente a novas dinâmicas econômicas ${ }^{1}$.

O surgimento da moeda, nesse contexto, não só aumentou o grau de especialização, bem como reduziu o tempo gasto nas trocas e eliminou a necessidade de dupla coincidência de desejos. Assim, a moeda passa a cumprir o papel de meio de pagamento ${ }^{2}$, reserva de valor ${ }^{3}$, unidade-padrão

\footnotetext{
${ }^{1}$ Para uma análise mais detida desse histórico, confira-se Congresso de Ciências Sociais Aplicadas - Responsabilidade Social e Consumo Sustentável, 2010, Setor de Ciências Sociais Aplicadas, UNICENTRO. A Evolução da Moeda no Contexto Histórico. 2010. 4 p. Disponível em: <https://anais.unicentro.br/concisa/iiiconcisa/pdf/resumo_105.pdf>. Acesso em: 16 set. 2018.

${ }^{2}$ Meio de pagamento consiste na "capacidade que a moeda tem de diminuir dívidas em última instância, ou seja, é um ativo financeiro de liquidez imediata. Em quase todas as transações de mercado na nossa economia, a moeda, na forma de dinheiro ou cheques, é um meio de pagamento. Ela é usada para pagar por bens e serviços. O uso da moeda como meio de pagamento promove eficiência econômica, eliminando muito do tempo gasto no intercâmbio de bens e serviços", conforme PINHEIRO, Juliano Lima. Mercado de Capitais. $8^{\mathrm{a}}$ ED. São Paulo: Editora Atlas, 2016. p. 13.

${ }^{3}$ Reserva de valor consiste em "ser um repositório de poder de compra sobre o tempo. Assim, uma reserva de valor é usada para poupar o poder de compra da hora em que a renda é recebida até a hora em que ela é gasta" Ibid.p. 14.
} 
de conta ${ }^{4}$ e intermediária de trocas entre os agentes ${ }^{5}$. Em um primeiro momento, os sistemas monetários foram baseados em metais, quais sejam, o ouro, a prata, o bronze e o ferro, uma vez que estes metais apresentavam as características necessárias para representarem um grande valor em um pequeno peso devido a sua raridade, durabilidade, divisibilidade $\mathrm{e}$ homogeneidade.

No final da Idade Média, devido às dificuldades e riscos no transporte de moedas metálicas, surgem as casas de custódia, nas quais as moedas de ouro e de prata eram depositadas e em troca se recebia um certificado de depósito. Com o passar do tempo, esse certificado de depósito passou a ser transferível, dando origem à moeda papel que, posteriormente, nos levou ao conceito de moeda fiduciária ${ }^{6}$.

Isto é, em razão das dificuldades em se manter uma relação estável entre a moeda e o bem econômico que servia de lastro, acabou-se por consolidar a moeda fiduciária, cujo valor está, em grande medida, atrelado à confiança do detentor deste bem intermediário de troca na autoridade central emissora.

Neste sentido, a moeda fiduciária cumpre o papel de unidade de conta ao ser utilizada como meio uniforme para expressar aquilo que ela representa ou seu valor. Nas palavras de Sztajn e Barossi-Filho ${ }^{7}$, a função de unidade de conta da moeda “(...) é convencional e se assemelha a um sinal, unifica a informação do que aquela moeda representa. A convenção permite representar, exprimir em números o valor de posições ativas e passivas,

\footnotetext{
${ }^{4}$ Unidade-padrão de conta consiste na "função de fornecer uma unidade de conta, ou seja, criar mediação de valor na economia", Ibid. p. 14 .

${ }^{5}$ Por fim, ser uma intermediária de trocas geralmente aceito pelos agentes significa, em última análise, que "a moeda permite que cada um se especialize na produção de bens segundo sua especialidade", Ibid. p. 14.

${ }^{6}$ Nesse sentido, conferir: BACHA, Carlos José Caetano. Macroeconomia Aplicada à Análise da Economia Brasileira. São Paulo: Editora da Universidade de São Paulo, 2004. p.67.

${ }^{7}$ SZTAJN, R.; BAROSSI-FILHO, M. Natureza Jurídica da moeda e desafios da moeda virtual. In: Revista Jurídica Luso-Brasileira, Ano 1, n.1, Lisboa: Centro de Investigação de Direito Privado da Faculdade de Direito da Universidade de Lisboa (CIDP), 2015, p. 1681 apud., BINNIE, Ricardo; MARTINS, Alessandra Carolina Rossi. Criptomoeda: Considerações Acerca de sua Tutela Jurídica no Direito Internacional e Brasileiro. Revista de Direito Empresarial. São Paulo. v. 11. Set - Out / 2015. p. 196
} 
facilita valorá-las”. O seu valor decorre da confiança que a sociedade tem em quem emitiu o título, isto é, nos Bancos Centrais competentes tanto pela criação como pela circulação das moedas em cada país.

Com o desenvolvimento da internet, no século $\mathrm{XX}$, a moeda sofre novas modificações para se adequar às transformações sociais. É neste contexto que surgem as chamadas moedas digitais, conforme registrado por Nelson Abrahão:

Irrecusável a penetração dos meios eletrônicos na sociedade moderna, no espelho vivo do desenvolvimento, cujo espaço virtual apresenta a telemática como fator de progresso e da própria evolução de fatores que buscam sintetizar a importância do tempo como elemento agregado das operações bancárias, na confluência de mercados interligados e nas ordens emitidas, que priorizam a mantença do sigilo e a confiança no sistema. ${ }^{8}$

A digitalização da moeda, com o uso de cartões de débito e de crédito, trouxe diversos benefícios para a sociedade, pois ao substituir a necessidade do papel moeda, a moeda digital acaba por diminuir custos de transações e acarreta em uma melhor proteção jurídica e maior segurança a sociedade. Atualmente:

“(...) a moeda escritural é uma moeda que não existe materialmente senão nos livros de contabilidade do banco; existe apenas na forma escrita. (...). Os dígitos de nossas contas bancárias são as moedas escriturais modernas; a moeda escritural moderna é totalmente digital." ".

Assim, a moeda digital a qual nos referimos é também uma moeda estatal, emitida por uma autoridade legal, e difere-se da moeda papel pois não tem existência física e é somente escriturada em contas eletrônicas bancárias ou de outra espécie. A moeda digital está prevista na Lei $n^{\circ} 12.865$, de 9 de outubro de 2013, e sua regulamentação decorre de atos normativos editados pelo BACEN e diretrizes do CMN.

\footnotetext{
${ }^{8}$ ABRAHÃO, Nelson. Direito Bancário. 16 ed. São Paulo: Saraiva, 2016. p. 650.

${ }^{9}$ ULRICH, Fernando. Aspectos econômicos dos Bitcoins. Apud. BARBOSA, Tatiana Casseb B. M. A Revolução das Moedas Virtuais: Bitcoins e Altcoins. São Paulo: Revoar, 2016. Cap. 2.
} 
No início dos anos 90, em São Fransciso, Eric Hughes, Timothy C. May e John Gilmore juntaram um grupo de criptógrafos e hackers que deram origem ao movimento "Cypherpunk", cujo objetivo era proteger a privacidade da população na era digital. Com o estudo da matemática e criptografia, aplicado à filosofia de privacidade e respeito à liberdade individual na internet, surge a ideia da criptomoeda, uma moeda descentralizada e eletrônica como alternativa para realização de pagamentos e uma diminuição nos custos de transação atrelados aos sistemas de pagamento tradicionais ${ }^{10}$.

Após a crise de 2008, as discussões sobre as criptomoedas retornaram com a proposta de descentralizar o poder financeiro. Nas palavras de André Franco e Vinícus Bazan “(...) Uma saída seria dar às pessoas a posse e o controle de seu próprio dinheiro, para que não precisassem mais de instituições intermediando suas transações" ${ }^{11}$.

Neste cenário, em 2008, com base no projeto criado por Satoshi Nakamoto, surge o sistema Bitcoin, conforme descrito em seu artigo "Bitcoin: A Peer-to-Peer Electronic Cash System". O artigo apresenta, pela primeira vez, uma proposta de pagamento online, por meio de dinheiro eletrônico, sem a participação de uma instituição financeira. A ideia, nas palavras de Satoshi Nakamoto é “ (...) um sistema de pagamento eletrônico baseado em prova criptográfica em vez de confiança, permitindo que quaisquer duas partes dispostas negociem diretamente entre si sem a necessidade de um terceiro de confiança." ${ }^{12}$.

\footnotetext{
10 "Privacy is necessary for an open society in the electronic age. (...) Since we desire privacy, we must ensure that each party to a transaction have knowledge only of that which is directly necessary for that transaction. (...) We cannot expect governments, corporations, or other large, faceless organizations to grant us privacy out of their beneficence. (...) We must defend our own privacy if we expect to have any. We must come together and create systems which allow anonymous transactions to take place (...) Cypherpunks write code. We know that someone has to write software to defend privacy, and since we can't get privacy unless we all do, we're going to write it." (HUGHES, Eric. A Cypherpunk's Manifesto. 1993. Disponível em <https://medium.com/mediumbrasil/manifesto-de-um-cypherpunk-3c678c4898c5. 1993> Acesso em 15 de set. 2018)

${ }^{11}$ FRANCO, André; BAZAN, Vinicius. Criptomoedas: melhor que dinheiro. São Paulo : Empiricus, 2018. p. 42.

${ }^{12}$ NAKAMOTO, Satoshi. Bitcoin: A Peer-to-Peer Electronic Cash System. p. 1. Disponível em $<$ https://bitcoin.org/bitcoin.pdf> Acesso em 15 de set. 2018.
} 
Forma-se então um novo fluxo financeiro, em uma estrutura fechada e centralizada, oferecendo uma opção acessível a todos aqueles que não tiverem interesse na utilização do sistema bancário tradicional ${ }^{13}$. Nas palavras de Andreas Antonopolus:

O bitcoin representa uma transformação fundamental do dinheiro. Uma invenção que muda a tecnologia mais antiga que temos na civilização. Isso muda radical e disruptivamente, mudando a arquitetura fundamental para uma onde cada participante é igual. Onde a transação não tem estado ou contexto além de obedecer às regras de consenso da rede que ninguém controla. Onde seu dinheiro é seu. Você controla absolutamente tudo através da aplicação de assinaturas digitais, e ninguém pode censurá-lo, ninguém pode aproveitá-lo, ninguém pode congelá-lo. Ninguém pode dizer o que fazer ou o que não fazer com seu dinheiro. É um sistema de dinheiro que é simultâneo, absolutamente transnacional e sem fronteiras. Nós nunca tivemos um sistema de dinheiro assim. ${ }^{14}$

\subsection{As Criptomoedas}

A proposta das criptomoedas é permitir a realização de pagamentos e operações financeiras eletrônicas diretamente entre os próprios usuários no chamado formato peer-to-peer ${ }^{15}$, isto é, sem a intermediação de instituições financeiras. Neste formato, o que as criptomoedas propõem é a superação do

\footnotetext{
13 "A atual maneira em que o sistema financeiro está estruturado demanda uma série de intermediários para que um simples pagamento seja realizado. Por exemplo, quando uma compra é feita com um cartão de crédito, um banco, uma operadora de cartão de crédito, um intermediário bancário e as partes que compram e vendem os produtos estão envolvidos, ou seja, um sistema complexo e gera uma série de custos na realização da transação. Quando as partes aderem ao uso da criptomoeda apenas o comprador, vendedor e partes verificadoras da transação (outros usuários do sistema da criptomoeda) estão envolvidas, gerando eficiências de mercado." conforme SILVA, Luis Gustavo Doles. Blockchain como Sistema de Custódia de Valores Mobiliários no Âmbito do Mercado de Capitais Brasileiros. Revista de Direito Bancário e do Mercado de Capitais. São Paulo. v. 80. Abr - Jun / 2018. p. 94.

${ }^{14}$ ANTONOPOLUS, Andreas. The internet of Money. 2016, Merkle Bloom LLC Apud. CAMPOS, Emília Malgueiro. Criptomoedas e blockchain: o dinheiro no mundo digital. Rio de Janeiro: Lume Juris, 2018. p. 32.

15 "Peer-to-peer (P2P) lending is a method of debt financing that enables individuals to borrow and lend money without the use of an official financial institution as an intermediary. Peer-to-peer lending removes the middleman from the process, but it also involves more time, effort and risk than the general brick-and-mortar lending scenarios. P2P lending is also known as social lending or crowdlending." (INVESTOPEDIA. Peer-To-Peer (P2P) Lending - What is Peer-To-Peer Lending $(P 2 P) . \quad D i s p o n i v e l \quad$ em $\quad$ https://www.investopedia.com/terms/p/peer-to-peerlending.asp\#ixzz5WB56KHRJ>Acesso em 16 de set de 2018)
} 
modelo de segurança fundado na confiança no intermediário por um sistema baseado na prova criptográfica ${ }^{16}$.

Esse propósito é alcançado por meio da tecnologia blockchain, pela qual é possível registrarem-se todas as operações realizadas com a criptomoeda de maneira escalonada, funcionando como uma grande escrituração contábil de caráter público, permitindo que cada usuário ateste a veracidade e a sequência de cada operação realizada. Ao lado dessa função essencial de servir como um meio de pagamento, as criptomoedas vêm sendo utilizadas como um instrumento alternativo de levantamento de fundos para novos negócios por meio de ICOs, objeto de estudo do presente trabalho.

Em outras palavras, as criptomoedas são lançadas publicamente na internet em diversos sites para financiar projetos de variados tipos ou apenas para os usuários a terem como moeda, pois são adquiridas pelos investidores interessados em participar do projeto ou serem titulares das criptomoedas emitidas.

Com base no exposto acima, chegamos a definição de criptomoeda como um bem digital gerado com base na tecnologia blockchain, baseada em criptografia. São algoritmos distribuídos e uma rede descentralizada de usuários, independentemente de qualquer país soberano, e ainda, divisível, com conteúdo personalizável, tendo o seu valor definido não por lastro como outras moedas, mas sim pelo interesse do mercado na sua utilização.

\subsection{A Natureza Jurídica das Criptomoedas}

\footnotetext{
16 "With the possibility of reversal, the need for trust spreads. (...) What is needed is an electronic payment system based on cryptographic proof instead of trust, allowing any two willing parties to transact directly with each other without the need for a trusted third party. Transactions that are computationally impractical to reverse would protect sellers from fraud, and routine escrow mechanisms could easily be implemented to protect buyers. In this paper, we propose a solution to the double-spending problem using a peer-to-peer distributed timestamp server to generate computational proof of the chronological order of transactions."(NAKAMOTO, Satoshi. Op. Cit., p. 1)
} 
A definição da natureza jurídica ${ }^{17}$ das criptomoedas é de grande importância para compreensão de suas consequências legais. Neste ponto, deve-se ter em mente que as discussões em diversos países vêm definindo as criptomoedas de distintas formas e não há qualquer tipo de consenso a respeito de sua natureza jurídica.

Em um primeiro momento, focaremos apenas nas discussões à luz do direito brasileiro, tendo em vista que os órgãos reguladores do Brasil estão encontrando grande dificuldade em definir, de forma consistente e tecnicamente fundamentada, a natureza jurídica do instituto.

\section{a) Moedas Fiduciárias}

Juridicamente, não se pode comparar as criptomoedas com a moeda fiduciária, já que apenas é considerada moeda aquela que apresentar "curso legal", isto é, aquela que é aceita por toda a sociedade como meio de troca.

No Brasil, o curso legal foi implementado e regulado pela Lei $\mathrm{n}^{\circ}$ 9.069, de 29 de junho de 1995, que dispõe em seu art. $1^{\circ}$ que "A partir de $1^{\circ}$ de julho de 1994, a unidade do Sistema Monetário Nacional passa a ser o REAL, que terá curso legal em todo o território nacional.”. Desta forma, à luz do ordenamento jurídico brasileiro, se considerássemos as criptomoedas como moedas fiduciárias, teríamos que operações realizadas com base nestas não seriam dotadas de validade jurídica, sendo nulas de pleno direito (Art. $1^{\circ}$ da Lei $\mathrm{n}^{\circ}$ 10.192, de 14 de fevereiro de 2001 e Art. 318 do Código Civil Brasileiro $^{18}$ ).

Assim, por não estarem necessariamente associadas a uma determinação estatal, mas sim, a um pacto entre agentes baseado na

\footnotetext{
${ }^{17}$ Natureza jurídica consiste na "afinidade que um instituto jurídico tem, em diversos pontos, com uma grande categoria jurídica, podendo nela ser incluída a título de classificação", conforme DINIZ, Maria Helena. Dicionário Jurídico. São Paulo: Saraiva, 1996. p. 337.

${ }^{18}$ Art. 1o As estipulações de pagamento de obrigações pecuniárias exequíveis no território nacional deverão ser feitas em Real, pelo seu valor nominal.

Art. 318. São nulas as convenções de pagamento em ouro ou em moeda estrangeira, bem como para compensar a diferença entre o valor desta e o da moeda nacional, excetuados os casos previstos na legislação especial.
} 
confiança, pacto este fruto da autonomia privada, não é possível atribuir às criptomoedas curso legal e, consequentemente, considerá-las como moeda fiduciária.

\section{b) Moedas Digitais}

De acordo com a regulamentação do BACEN e do CMN, as moedas digitais são recursos armazenados em dispositivo ou sistema eletrônico que permitem ao usuário final efetuar transações de pagamento denominados em moeda nacional. Neste sentido, buscando esclarecer as diferenças entre as chamadas moedas digitais e as criptomoedas, o Banco Central emitiu o Comunicado $\mathrm{n}^{\mathrm{0}} 25.306$, de 19 de fevereiro de 2014:

As chamadas moedas virtuais não são emitidas nem garantidas por uma autoridade monetária. Algumas são emitidas e intermediadas por entidades não financeiras e outras não têm sequer uma entidade responsável por sua emissão. Em ambos os casos, as entidades e pessoas que emitem ou fazem a intermediação desses ativos virtuais não são reguladas nem supervisionadas por autoridades monetárias de qualquer país. $^{19}$

Além de esclarecer que as criptomoedas não são consideradas moedas digitais nos termos da legislação aplicável, bem como não são garantidas por qualquer autoridade monetária, o comunicado do BACEN realça os riscos envolvidos em seu uso, considerando que estas não tem garantia de conversão para a moeda oficial do país e que o valor de conversão deste ativo depende exclusivamente da credibilidade e confiança que os agentes de mercado possuem na aceitação desta moeda como meio de troca e expectativa de sua valorização.

Por meio do Comunicado no 31.379 de 16 de novembro de 2017, o BACEN manifestou-se novamente sobre o tema, indicando os riscos de operações de guarda e negociação de criptomoedas e reiterando as diferenças

\footnotetext{
${ }^{19}$ Banco Central Do Brasil. Comunicado $n^{\circ} 25.306$, de 19 de fevereiro de 2014. Disponível em $<$ https://www3.bcb.gov.br/normativo/detalharNormativo.do?method=detalharNormativo\&N=1140 09277> Acesso em 18 de set. de 2018.
} 
entre as criptomoedas e as moedas digitais. Nesta ocasião, o BACEN proibiu a utilização das criptomoedas para operações que representem transferências internacionais de valores, mencionando que estas são caracterizadas como câmbio e são de realização exclusiva das instituições autorizadas.

O BACEN, por meio deste mesmo comunicado, afastou de sua competência a regulamentação e supervisão das criptomoedas, de tal forma que operações ilícitas que as utilizam, incluindo os ICOs, não contam com o seu controle.

Não há, no arcabouço legal e regulatório relacionado com o Sistema Financeiro Nacional, dispositivo específico sobre moedas virtuais. O Banco Central do Brasil, particularmente, não regula nem supervisiona operações com moedas virtuais. ${ }^{20}$

Isto é, seguindo o entendimento do BACEN, as criptomoedas não se confundem com a moeda digital, dado que esta é a própria moeda corrente do país, com curso legal, expressa em meio eletrônico, enquanto as criptomoedas não são referenciadas em reais ou em outras moedas estabelecidas por governos soberanos.

\section{c) A Natureza Híbrida das Criptomoedas}

É importante deixar claro que as criptomoedas, além de conferirem um crédito ao seu titular, também podem ser utilizadas como um direito dentro da rede ou ainda como uma forma de investimento pelo qual será conferido ao investidor uma remuneração proveniente dos resultados obtidos. Nesse sentido, parte da doutrina utiliza o termo criptoativos na tentativa de abranger todos os títulos distribuídos pelo sistema blockchain.

Desta forma, pensar na criptomoeda utilizada como um direito de crédito facilita sua comparação com os institutos da moeda digital e da moeda

\footnotetext{
${ }^{20}$ Banco Central Do Brasil. Comunicado no 31.379 de 16 de novembro de 2017. Disponível em $<$ https://www.bcb.gov.br/pre/normativos/busca/normativo.asp?numero=31379\&tipo=Comunicado \&data $=16 / 11 / 2017>$ Acesso em 18 de set. de 2018.
} 
fiduciária, entretanto, considerando que as criptomoedas são utilizadas de diversas formas, Emília Campos $^{21}$ defende a fungibilidade da natureza jurídica das criptomoedas.

No caso de um usuário que adquire criptomoedas buscando uma simples valorização para realização futura, a utilização do ativo está se dando a título de reserva de valor, com intenção de lucro, indicando a função clara de investimento. Neste caso, a Receita Federal do Brasil estabelece que, como ativo, as criptomoedas estão sujeitas às regras de ganho de capital, quando da realização, ou seja, venda. Isto é, considerando que os ativos também podem ser comercializados, doados e transmitidos como herança, também comporão a base para a tributação específica de transmissão de bens por sucessão.

Em uma segunda hipótese, na qual as criptomoedas são utilizadas para pagamento de um bem, deve-se aplicar os efeitos inerentes à operação de compra e venda. Por fim, no caso do uso da criptomoeda como uma ativo representativo de um direito dentro da rede, não se aplicam os efeitos jurídicos citados acima, tendo em vista que as operações ocorrem apenas na rede.

Para Emília Campos, o importante é considerar a função principal da criptomoeda, respeitando-se sua fungibilidade intrínseca, como forma a definir o tratamento a esta conferido:

\footnotetext{
Verifica-se, portanto, que fica muito mais fácil, e útil, entender a natureza jurídica dos criptoativos analisando-os sob a perspectiva de sua função, do que pura e simplesmente o instituto em si. Em razão dos pontos expostos, para efeitos de definição da natureza jurídica, defendo a aplicação do que chamo de princípio da fungibilidade dos criptoativos. Essa distinção também tem impacto no âmbito da regulamentação do tema. ${ }^{22}$
}

${ }^{21}$ CAMPOS, Emília Malgueiro. Op. Cit., p.28-32

${ }^{22}$ Ibid. p.30 


\section{CAPÍTULO 2 - OS VALORES MOBILIÁRIOS}

Considerando a proposta do presente trabalho, torna-se necessária uma exposição clara e precisa sobre os valores mobiliários, conforme apresentados pela doutrina, para que possamos concluir sobre a possível classificação da natureza jurídica das criptomoedas, à luz da legislação brasileira, como um valor mobiliário.

Durante as discussões para uma definição sobre o conceito como hoje o conhecemos, o legislador brasileiro utilizou como base o direito norteamericano, que conceitua de forma mais abrangente os valores mobiliários.

\subsection{A evolução do conceito de securities no direito norte- americano e o Howey Test}

As discussões sobre a definição de securities, bem como a necessidade de um órgão regulador, surgem após a crise da Bolsa de Nova York de 1929, momento no qual a estrutura do mercado de capitais norte-americano expôs a sua fragilidade e deflagrou uma série de medidas visando assegurar aos investidores do mercado de valores mobiliários uma maior proteção.

Neste primeiro momento, após a enumeração exemplificativa estabelecida no Securities Act de 1933 (Section $2^{23}$ ) do que seria considerado como security, os tribunais norte-americanos passaram a enfrentar diversos casos concretos buscando delimitar esse conceito. Aponta-se como leading

\footnotetext{
${ }^{23}$ SEC. 2 (a) DEFINITIONS. - When used in this title, unless the context otherwise requires- (1) The term "security" means any note, stock, treasury stock, security future, security-based swap, bond, debenture, evidence of indebtedness, certificate of interest or participation in any profitsharing agreement, collateral-trust certificate, preorganization certificate or subscription, transferable share, investment contract, voting-trust certificate, certificate of deposit for a security, fractional undivided interest in oil, gas, or other mineral rights, any put, call, straddle, option, or privilege on any security, certificate of deposit, or group or index of securities (including any interest therein or based on the value thereof), or any put, call, straddle, option, or privilege entered into on a national securities exchange relating to foreign currency, or, in general, any interest or instrument commonly known as a "security", or any certificate of interest or participation in, temporary or interim certificate for, receipt for, guar antee of, or warrant or right to subscribe to or purchase, any of the foregoing.
} 
case da conceituação de valores mobiliários o julgamento, ocorrido nos Estados Unidos em 1946, do caso SEC v. W. J. Howey \& Co.

Em uma breve síntese, a discussão versava sobre a venda de terrenos a centenas de pessoas por uma companhia com a assunção do compromisso de, em contrapartida, prestar serviços de plantio de terra e de comercialização dos produtos colhidos. A Suprema Corte entendeu que esta oferta, isto é, uma oportunidade de negócio oferecida a um número elevado de pessoas, não constituía uma simples venda de terras para plantio e que, na realidade, caracterizava a oferta de um "contrato de investimento" devendo ser previamente registrada na SEC.

Em sua decisão, a Suprema Corte definiu que "a security compreende o investimento de dinheiro em um empreendimento comum, no qual a expectativa de lucros depende unicamente dos esforços de terceiros". Esta definição deu origem ao chamado Howey Test, de forma que, são considerados valores mobiliários não somente os títulos tradicionalmente emitidos por uma sociedade anônima, mas também qualquer "contrato de investimento", considerando-se como tal, aquele correspondente a (i) investimento em dinheiro; (ii) em um empreendimento comum; (iii) no qual se tenha expectativa de lucro; e (iv) que estes dependam exclusivamente dos esforços de terceiros ${ }^{24}$.

\section{a) Investimento em Dinheiro}

Para a definição de investimento em dinheiro, deve-se ter em mente que a definição de security não está limitada às hipóteses em que há pagamento exclusivamente em moeda corrente, podendo também ser realizado com qualquer outro bem que apresente valor. O importante nesta definição é o investimento, ou melhor, o investimento com expectativa de retorno financeiro.

\footnotetext{
${ }^{24}$ Para maiores detalhes sobre os requisitos definidos no Howey Test, veja EIZIRIK, Nelson et al. Mercado de Capitais - Regime Jurídico. $3^{\mathrm{a}}$ Ed. Rio de Janeiro: Renovar. 2011. p. 34-50
} 


\section{b) Empreendimento Comum}

A noção de empreendimento comum remonta à ideia de que o valor mobiliário é oferecido a diversas pessoas, que partilham um mesmo conjunto de ativos, com a expectativa de auferir lucros decorrentes dos esforços do promotor do negócio ou do instrumento que está sendo ofertado.

De acordo com Ary Oswaldo Mattos Filho ${ }^{25}$, apesar do empreendimento comum se manifestar, normalmente, na existência de uma pessoa jurídica, que emite ou entrega os valores mobiliários na proporção dos investimentos recebidos, a inexistência de pessoa jurídica não descaracteriza o valor mobiliário. Isto é, o que é relevante é a existência do interesse comum no sucesso do empreendimento, sendo indiferente que este último seja emitido ou tenha suas obrigações nascidas de uma pessoa jurídica ou física. O fundamento da comunhão é a existência de interesse econômico interligado juridicamente.

\section{c) Expectativa de Lucro}

A "expectativa de lucro" consiste na expectativa de quem o adquire de obter algum tipo de benefício ou ganho em virtude do investimento realizado, distinguindo-se, por tal situação, da simples compra para consumo. Isto é, quem negocia um valor mobiliário está atrás de ganhos financeiros, buscando uma maneira de investir sua poupança particular.

\section{d) Desempenho exclusivo de Terceiros}

\footnotetext{
${ }^{25}$ FILHO, Ary Oswaldo Mattos. O Conceito de Valor Mobiliário. Revista de Administração de Empresas. Rio de Janeiro. Abr - Jun / 1985. p. 43. Disponível em <http://www.scielo.br/pdf/rae/v25n2/v25n2a03> Acesso em 20 de out. de 2018.
} 
A grande discussão da jurisprudência em relação a este requisito decorre da ideia que a expectativa de lucro proviria exclusivamente dos esforços de terceiros. Neste sentido, as atuais decisões da corte norteamericana entendem que ainda que requeiram algum esforço ou participação dos investidores, os instrumentos ou negócios ofertados podem ser considerados contratos de investimento, e, consequentemente, valores mobiliários, se as funções ou obrigações essenciais para o sucesso do empreendimento tenham sido desenvolvidas por terceiros:

Originariamente se entendia que o valor mobiliário seria caracterizável se o lucro adviesse do esforço exclusivo de terceiro que não o próprio investidor. Posteriormente, entretanto, se verificou a existência de valor mobiliário, em cuja transação o investidor passa a ter uma parcela de influência na tentativa de obtenção do lucro. ${ }^{26}$

O conceito do Howey Test será de suma importância para a análise do ICO proposta no capítulo abaixo, na medida em que devemos analisar os diferentes tokens objetos de oferta de ICO, utilizando como teste os requisitos acima elencados.

\subsection{Os Valores Mobiliários no Direito Brasileiro}

Seguindo o entendimento de Nelson Eizirik ${ }^{27}$, os valores mobiliários diferem de outros bens em alguns aspectos fundamentais, quais sejam (i) não possuírem valor intrínseco, isto é, não possuírem valor em si; (ii) não serem produzidos ou fabricados para serem usados ou consumidos, mas sim, serem emitidos e depois ofertados aos investidores, que podem negociá-los no mercado secundário a preços variáveis e por um número indeterminado de vezes; e (iii) apesar de sua natureza fungível, os ativos considerados valores mobiliários, atribuem a seus titulares diferentes direitos e são utilizados para diversas utilidades.

\footnotetext{
${ }^{26}$ FILHO, Ary Oswaldo Mattos. Op. Cit. p. 44.

${ }^{27}$ EIZIRIK, Nelson et al. Op Cit. p. 23
} 
Com base no acima exposto, o legislador brasileiro buscou definir os valores mobiliários na Lei $\mathrm{n}^{\circ} 6.385$ de 7 de dezembro de 1976 (Art. $2^{\text {o28}}$ ). Esta conceituação não buscou apenas delimitar o que deve ser considerado como valor mobiliário, mas também delimitar o campo de atuação dos órgãos do poder executivo encarregados. Nas palavras de Otávio Yazbeck:

De qualquer forma, porém, o conceito de valor mobiliário, que a lei evita, adotando apenas uma relação de instrumentos, cada vez mais ampliada, destina-se muito mais a estabelecer o campo de incidência das regras estabelecidas pelo diploma. ${ }^{29}$

\subsection{As criptomoedas como títulos ou contratos de investimento coletivo}

A grande discussão decorre da possível configuração das criptomoedas como títulos ou contratos de investimento coletivo, nos termos do inciso IX do Art. $2^{\circ}$ da Lei 6.385. Esta análise toma destaque ao considerarmos as criptomoedas como contratos complexos que surgem de um conjunto de relações jurídicas entre os participantes, isto é, um conjunto

\footnotetext{
${ }^{28}$ Art. 2o São valores mobiliários sujeitos ao regime desta Lei:

I - as ações, debêntures e bônus de subscrição;

II - os cupons, direitos, recibos de subscrição e certificados de desdobramento relativos aos valores mobiliários referidos no inciso II;

III - os certificados de depósito de valores mobiliários;

IV - as cédulas de debêntures;

$\mathrm{V}$ - as cotas de fundos de investimento em valores mobiliários ou de clubes de investimento em quaisquer ativos;

VI - as notas comerciais;

VII - os contratos futuros, de opções e outros derivativos, cujos ativos subjacentes sejam valores mobiliários;

VIII - outros contratos derivativos, independentemente dos ativos subjacentes; e

IX - quando ofertados publicamente, quaisquer outros títulos ou contratos de investimento coletivo, que gerem direito de participação, de parceria ou de remuneração, inclusive resultante de prestação de serviços, cujos rendimentos advêm do esforço do empreendedor ou de terceiros.

$\S 1$ o Excluem-se do regime desta Lei:

I - os títulos da dívida pública federal, estadual ou municipal;

II - os títulos cambiais de responsabilidade de instituição financeira, exceto as debêntures.

${ }^{29}$ YAZBECK, Otávio. Regulação do mercado financeiro e de capitais. 2 ed. Rio de Janeiro: Elsevier, 2007. p. 316
} 
de regras conhecidas aplicáveis aos seus participantes que não podem ser modificadas salvo por consenso ${ }^{30}$.

Sob esta perspectiva, estaríamos diante de um instituto composto por um complexo de relações jurídicas, mais próximo de um contrato, e por consequência, de um valor mobiliário propriamente dito ao considerarmos o investimento realizado. Isto é, na medida em que investidores celebrem contratos para aquisição de criptomoedas para fins de investimento, como ocorre em alguns casos de ICO, tais instrumentos financeiros serão considerados, para todos os fins, como valores mobiliários.

Neste sentido, apontamos a principal decisão judicial sobre o tema no âmbito da ação judicial movida pela SEC em face da Bitcoin Savings and Trust e seu administrador Trendon T. Shavers ${ }^{31}$. A SEC emitiu parecer a respeito de sua competência para agir determinando que as criptomoedas, neste caso específico, se enquadram no conceito de security, na medida que os contratos celebrados entre a Bitcoin Saving and Trust e os investidores eram contratos de investimento.

$\mathrm{O}$ atual entendimento da doutrina e da CVM é que o conceito estabelecido no inciso IX trouxe ao direito brasileiro o conceito de security do direito norte-americano, em particular o chamado Howey Test ${ }^{32}$. Desta

\footnotetext{
${ }^{30}$ MANTILLA, S.E. Bitcoin: La outra cara de la moneda. Buenos Aires: IEI - Instituto de Estratégia Internacional, 2014, p. 34 apud. BINNIE, Ricardo; MARTINS, Alessandra Carolina Rossi. Op, Cit. p. 197

${ }^{31}$ Estados Unidos da América. United States District Court Eastern District of Texas. Memorandum Opinion $\mathrm{n}^{\mathrm{o}}$ Case 4:13-cv-00406-RC-ALM. SECURITIES AND EXCHANGE COMISSION. TRENDON T. SHAVERS and BITCOIN SAVINGS AND TRUST. Relator: Ammos L. Mazzant, United States Magistrate Judge. Eastern District of Texas, TE, 06 de janeiro de 2013. Memorandum Opinion Regarding the Court's Subject Matter Jurisdiction. Disponível em <https://www.sec.gov/litigation/complaints/2013/comp-pr2013-132.pdf> Acesso em 09 de out de 2018.

32 "2.8 O inciso IX foi claramente inspirado em decisões da Suprema Corte dos Estados Unidos a respeito do conceito de security, em particular, no caso SEC v. W. J. Howey Company. Neste caso, a Suprema Corte decidiu adotar um "princípio flexível e não estático, capaz de se adaptar aos variáveis e incontáveis arranjos criados por aqueles que captam dinheiro de terceiros". 2.9 Segundo a definição que consta em Howey, o conceito de security deve abranger "qualquer contrato, negócio ou arranjo por meio do qual uma pessoa investe seu dinheiro em um empreendimento comum e espera receber lucros originados exclusivamente dos esforços do empreendedor ou de terceiros." (Comissão de Valores Mobiliários (CVM). Processo CVM n RJ2007/11.593, Registro Col. $\mathrm{n}^{\circ}$ 5730/07. Voto do Diretor Marcos Barbosa Pinto. Julgado em: 15 de janeiro de 2008. Disponível em <http://www.cvm.gov.br/export/sites/cvm/decisoes/anexos/0004/5615-0.pdf> Acesso em 09 de out. de 2018.)
} 
forma, tendo em vista os diferentes tokens objeto de oferta, propomos a análise de cada um, de acordo com suas características específicas para que, observando o Howey Test, possamos verificar uma possível configuração dos ICOs como ofertas de valores mobiliários. 


\section{CAPÍTULO 3 - O CONCEITO DO INITIAL COIN OFFERING}

Initial Coin Offering é um mecanismo de investimento que tem se desenvolvido fortemente e cada vez mais, com o desenvolvimento da tecnologia do blockchain, vem superando outras formas de investimento. $\mathrm{O}$ primeiro ICO foi realizado em 2013 pela Mastercoin, uma criptomoeda construída sobre a blockchain do bitcoin que conseguiu arrecadar mais de 5 milhões de dólares. Após o sucesso, outras empresas seguiram o exemplo resultando em quase US $\$ 6$ bilhões (R $\$ 20,2$ bilhões) em 2018, destinados a 171 projetos diferentes, de acordo com o site CoinSchedule. O valor é maior do que o registrado durante todo o ano de 2017, quando 210 ICOs movimentaram US $\$ 3,8$ bilhões (R $\$ 12,81$ bilhões) ${ }^{33}$.

De acordo com Jarbas Andrade Manchioni ${ }^{34}$, são diversas as operações de ICOs baseadas em criptomoedas, algumas tendo como objeto apenas a propriedade de alguma criptomoeda ou o direito à aquisição dela $\mathrm{e}$ outras realizadas para financiar um projeto. A análise aprofundada do projeto, buscando identificar as características do produto oferecido bem como as expectativas geradas pela aquisição deste é de grande importância para avançarmos em sua análise jurídica.

\subsection{A Definição}

Em uma tradução literal do termo, o initial coin offering é uma oferta inicial de coins. Trata-se de uma arrecadação de fundos para o projeto de criptomoeda lançado, mediante a "venda" de criptomoedas no mercado para potenciais investidores que acreditem nesses projetos, nos fundamentos da empresa que a lança no mercado e na sua equipe de desenvolvedores, em

\footnotetext{
${ }^{33}$ Cryptocurrency $\quad$ ICO $\quad$ Stats $2018 . \quad$ Disponível em <https://www.coinschedule.com/stats.html?year=2018> Acesso em 13 de out de 2018.

${ }^{34}$ MANCHIONI, Jarbas Andrade. "ICO" e as Criptomoedas: Regime Jurídico e suas Incertezas. Revista de Direito Bancário e do Mercado de Capitais. Rio de Janeiro. v. 80. Abr - Jun / 2018. p. 19.
} 
troca de ativos virtuais, chamados de tokens. Isto é, diferentemente da oferta pública de valores mobiliários como hoje a conhecemos, o investidor receberá um token, que nem sempre lhe dará certos direitos societários ou de crédito contra a emitente, podendo apresentar diferentes funções e, por consequência, diferentes naturezas jurídicas.

Na definição de Emília Campos ${ }^{35}$, os tokens são bens intangíveis, ou seja, representações digitais, baseados em criptografia, de direitos que são garantidos aos seus detentores, quais sejam: (i) função de valor, quando tratamos propriamente de criptomoedas; (ii) direito a uma parcela das receitas de um empreendimento digital, representado por uma plataforma, vendido antecipadamente como método de financiamento de negócio; (iii) direito de aquisição de um determinado serviço/produto oferecido pela plataforma digital, tendo esse token a característica de criptomoeda de serviço; ou (iv) direito de receber juros e rendimentos por transações de valores.

A estrutura de um ICO pode diferir de acordo com as necessidades dos desenvolvedores ou fundadores. No entanto, quase todos eles têm os seguintes passos em comum: (i) a elaboração e publicação do White Paper; (ii) a pré-venda de tokens; (iii) uso de receitas e execução do projeto; e (iv) lançamento da rede onde os investidores e desenvolvedores começam as vendas dos tokens para o público.

\subsection{O Procedimento}

Os ICOs têm início com a disponibilização ao público do chamado White Paper na qual estão descritas as principais características do projeto, tais como, seus objetivos, cronogramas, o tempo envolvido e sua experiência e, ainda, a tecnologia que dará as informações financeiras. Em outras palavras, o White Paper é essencialmente um plano de negócios dos projetos

\footnotetext{
${ }^{35}$ CAMPOS, Emília. Op. Cit. p. 96 e 97
} 
que serão financiados pelo ICO. O primeiro White Paper decorreu do trabalho de Satoshi Nakamoto sobre Bitcoin e acabou sendo utilizado como modelo para os demais ICOs.

Uma vez que a estrutura de um White Paper ainda não foi regulamentada, os participantes do mercado estão começando a encontrar um terreno comum sobre qual deve ser o conteúdo deste documento, sendo certo que esta falta de padronização precisa ser resolvida o quanto antes, a fim de evitar vários problemas, incluindo uma possível divulgação seletiva e falta de comparabilidade.

Em aproximadamente $70 \%$ dos ICOs realizados, existe uma "prévenda" dos tokens. Nestes casos, o fundador permite que os investidores comprem tokens antes do crowdsale começar. A ideia principal de uma prévenda é fornecer desconto aos investidores, isto é, os compradores que participam deste momento do investimento muitas vezes obtêm preços mais baratos por token. Após a pré-venda, a empresa pode começar a construir a rede ou desenvolver o projeto descrito no seu White Paper.

Uma vez desenvolvida a rede, a empresa vende parte de seus tokens em troca de criptomoedas. O crowdsale é então o núcleo de um ICO, na medida que é o momento no qual os fundos são levantados.

\section{3. $\mathrm{O}$ conceito e as características dos tokens}

A doutrina ainda não apresentou uma classificação unificada referente aos tokens, tendo em vista que estes podem diferir de um para outro, e países podem até ter classificação diferentes para se referir a tokens semelhantes. Buscando delimitar o escopo de estudo proposto no presente trabalho, focaremos em sua classificação jurídica.

Manchioni $^{36}$ destaca os três tipos mais comuns de token, sendo estes o equity token, o debt token e o utility token:

\footnotetext{
${ }^{36}$ MANCHIONI, Jarbas Andrade. Op. Cit. p. 19 e 20
} 
(a) Utility Tokens: são aqueles baseados na criação de moedas virtuais utilizadas para acessar serviços disponibilizados pela própria plataforma financiada. Ao adquirirem um utility token, os investidores acabam investindo na capitalização para fundação do projeto, e estes poderão ser utilizados como forma de adquirir serviços nesta mesma plataforma.

(b) Debt Tokens: neste caso, o token confere basicamente ao seu titular um direito de crédito relativo a qualquer espécie de ativo negociável. Isto é, funcionam basicamente como um empréstimo que o investidor faz à rede, em troca de juros.

(c) Equity Token / Security Token: o investimento baseado em equity token é usado para apoiar financeiramente o projeto em seu início e o retorno dos investidores será na forma de dividendos, ou seja, participação efetiva e direta na receita gerada pela plataforma. Nesse caso, os tokens tem efetivamente função de ações ou participações nos empreendimentos, gerando dividendos, podendo ou não garantir direito de voto ou manifestação nos projetos. Em resumo, este token confere ao seu titular acesso a direitos societários, fazendo isto de maneira mais transparente na medida em que a votação seria conduzida através do sistema blockchain. Este é o tipo de ICO mais parecido com uma oferta de valores mobiliários, o qual atrairia a competência de supervisão da CVM e objeto de estudo do presente trabalho.

Os ICOs podem ter um ou combinar outros tipos de tokens em uma mesma oferta. A rigor, nos casos em que os tokens deem direitos apenas a aquisição de serviços ou à conversão em criptomoedas, quais sejam os utility 
tokens e os debt tokens, respectivamente, estes escapariam da definição de valor mobiliário proposta no presente trabalho.

\subsection{Os Utility Tokens e o Inital Coin Offering}

Conforme mencionado acima, os utility tokens, também conhecidos como app coins, não possuem valor financeiro, uma vez que fornecem aos usuários apenas acesso futuro a um produto ou serviço dentro da plataforma. Assim, por meio dos ICOs de utility tokens, as start-ups podem levantar capital para financiar o desenvolvimento de seus projetos de blockchain, e os usuários podem adquirir acesso futuro a esse serviço. Vale dizer que os utility tokens não são projetados como investimentos e ainda que muitas pessoas contribuam para os ICOs de utility tokens na esperança de que o valor dos tokens aumente à medida que a demanda pelo produto ou serviço da empresa também aumente, não há qualquer garantia, dependendo de sua valorização e sucesso do ICO.

A CVM se manifestou recentemente durante a análise do ICO da Niobium, afastando de sua jurisdição a regulamentação das ofertas de utility tokens. Nesta mesma oportunidade, a PFE corroborou o entendimento da SRE "no sentido de que o Niobium constitui um utility token e, portanto, não possui a natureza jurídica de valor mobiliário na feição de Contrato de Investimento Coletivo" e "sua oferta pública não atrai a competência da CVM de sorte a gerar a edição de uma stop order"37.

A oferta da Niobium teve início em agosto de 2017, como forma de impulsionar e promover a BOMESP. De acordo com o site da bolsa, ali "qualquer empresa poderá ter sua própria moeda ou poderá operar no mundo

\footnotetext{
37 "Em sua análise, a SRE concluiu que a Niobium não poderia ser caracterizada como valor mobiliário nos termos do art. $2^{\circ}$, IX, da Lei ${ }^{\circ} 6.385 / 76$, notadamente em razão de não haver remuneração, participação ou parceria oferecidas aos investidores, conforme o Memorando $\mathrm{n}^{\circ}$ 92/2017-CVM/SRE/GER-3." (Comissão de Valores Mobiliários (CVM). Processo SEI 19957.010938/2017-13, Reg. $\mathrm{n}^{\circ}$ 0888/18. Relator SRE. Julgado em: 30 de janeiro de 2018. Disponível em <http://www.cvm.gov.br/decisoes/2018/20180130_R1.html> Acesso em 14 de out. de 2018)
} 
das moedas virtuais". Durante duas fases de venda, 102 milhões de unidades de Niobium foram criadas, sendo a BOMESP $(45,5 \%)$ e os investidores $(46,2 \%)$ os maiores tomadores do criptoativo ${ }^{38}$.

Com a compra deste token, os usuários poderiam aplicá-los na plataforma de blockchain criada em 2013 conhecida como Ethereum que, além de circular sua própria moeda (o Ether), permite outras aplicações como o ativo brasileiro. Após este ICO, a Niobium será o único ativo a circular dentro da BOMESP. Isto é, se uma grande empresa planeja lançar sua própria moeda virtual na Bolsa para fazer sua captação, a interessada deverá comprar Niobium no mercado, caso não tenha ainda em sua carteira.

Para a análise da oferta, a SRE utilizou como base o Howey Test, conforme citado acima. Neste sentido, não houveram dúvidas que na oferta do Niobium estaria caracterizado um investimento formalizado por um título e que este investimento foi coletivo, isto é, em um empreendimento comum, ofertado publicamente, por meio da divulgação de seu White Paper. Desta forma, a discussão da SRE se limitou a analisar se a oferta criaria alguma expectativa de lucro a seus investidores e se estes dependeriam exclusivamente dos esforços de terceiros.

Para tanto, foram analisadas as páginas do Facebook e Youtube relacionadas à BOMESP e Niobium Foudation e levantadas as seguintes questões (i) afirmação do representante da BOMESP no sentido que o Niobium seria classificada como uma "Gold Coin"; (ii) divulgação de regras de governança definidas no "smart contract" da BOMESP; e (iii) divulgação citando recebimento de "dividendos [...] distribuídos com inteligência aos seus investidores de acordo com suas apostas".

Em sua manifestação, a BOMESP esclareceu os apontamentos acima indicados na medida em que a referência a dividendos associa-se à remuneração que poderá ser obtida em algumas das "Colorfull Coins" cujos

\footnotetext{
${ }^{38}$ MENDES, Guilherme. ICO, oferta inicial de moedas virtuais, fomenta discussões jurídicas. Disponível em <https://www.jota.info/tributos-e-empresas/mercado/ico-discussao-juridica17042018> Acesso em 13 de out. de 2018.
} 
ICOs, no futuro, os desenvolvedores esperam que sejam realizados através da BOMESP, ao passo em que as regras de governança dizem respeito aos parâmetros estabelecidos em smart contracts registrados na rede blockchain "Ethereum" os quais governarão as funcionalidades e a operação da BOMESP, caracterizada como uma organização autônoma descentralizada. A BOMESP ressalta que, conforme descrito no White Paper da operação, o Niobium não conferirá qualquer remuneração aos seus detentores, a qualquer título, incluindo a título de dividendos ${ }^{39}$.

Desta forma, a CVM optou por seguir o entendimento da PFE em seu parecer no sentido que o Niobium, em princípio, não se enquadra na definição de Contrato de Investimento Coletivo ${ }^{40}$. Em resumo, após os esclarecimentos da BOMESP, a CVM entendeu em sua decisão que a obtenção de lucro, decorrente do bom andamento do projeto e consequente valorização do Niobium não caracterizaria “direito de participação, de parceria ou de

\footnotetext{
39 “[...] apesar de ter utilizado o vocábulo governança, o fez de forma atécnica e equivocada [...] A real intenção da frase foi informar que a BOMESP terá uma reserva de Niobiuns em sua posse, a ser utilizada como Utility Token na sua plataforma. É esse o sentido que o documento dá ao termo governança ainda que tal termo tenha significado usualmente aplicado a ele, principalmente no âmbito do direito societário e do mercado de capitais. [...] o fato de poder ser classificada, sob esse ângulo, como uma "goldcoin", não faz com que deixe de ter as características que a identifiquem como um Utility Token conforme, inclusive, é peremptoriamente e imediatamente afirmado em sequência:"... ela vai ser uma moeda de utilidade dentro da bolsa. Assim, o conceito (fluído) de "goldtoken" quando se limita a Tokens que possam ser consideradas, ainda que em tese, valores mobiliários ou equiparados. A efetiva análise deve se pautar - como já inclusive analisado pela área técnica - na presença dos requisitos legais para tanto. E, conforme já anteriormente esclarecido, ao adquirente do Niobium não é prometido nenhum ganho, lucro ou participação; mas apenas a aquisição de um ativo que poderá ter uma utilidade específica quando da implementação futura da BOMESP. Nesse ponto, trata-se de infeliz manutenção, por parte da equipe de marketing, ao misturar, equivocadamente, as possíveis funcionalidades que os smart contracts podem conferir a uma criptomoeda, como a própria Niobium. Entretanto, mais uma vez, é importante nos limitarmos ao que está explícito no White Paper - documento que efetivamente regula a emissão em questão. $\mathrm{O}$ Niobium não conferirá qualquer remuneração aos seus detentores, a qualquer título, incluindo a título de dividendos." (Comissão de Valores Mobiliários (CVM). Processo nº 19957.010938/201713. Memorando $\mathrm{n}^{\circ}$ 19/2017-CVM/SRE. Relator Dov Rawet - Superintendente de Registro de Valores Mobiliários. Emitido em: 27 de dezembro de 2017. Disponível em <http://www.cvm.gov.br/export/sites/cvm/decisoes/anexos/2018/20180130/088818_Manifestacao SRE.pdf> Acesso em 14 de out. de 2018)

40 "Nada obstante, a operação, a princípio, não se enquadra na definição de CIC, face ao disposto no art. $2^{\circ}$, IX, da Lei $6.385 / 76$, exatamente pela ausência de direito de participação, parceria ou remuneração, fundado em empreendimento comum [...]. Nesse passo, não se pode olvidar que o conceito de security, em nosso ordenamento jurídico, foi positivado, adquirindo contornos legais que limitam a sua configuração. Em vista do exposto, entende-se que a Niobium, em si mesma considerada, pode ser qualificada como um utility token e, como tal, atua como instrumento de troca que não se subsume ao conceito de contrato de investimento coletivo, embora haja expectativa de lucro, ainda que de caráter especulativo.” (Ibid. p. 4)
} 
remuneração, inclusive resultante de prestação de serviços, cujos rendimentos advêm do esforco do empreendedor ou de terceiros", nos termos do inciso IX do art. $2^{\circ}$ da Lei 6.385 .

Em sua decisão, o Colegiado buscou deixar claro que cada oferta de criptomoeda deverá ser analisada de acordo com suas características e que, a decisão no Caso Nioubium, em nada impacta em sua atuação no que se refere a eventuais ofertas nas quais os tokens sejam considerados valores mobiliários:

\begin{abstract}
No entanto, o Colegiado ressaltou que essa decisão circunscreve-se à análise da Niobium Coin, e em nada impacta a atuação desta Autarquia em relação a ofertas que envolvam produtos que, independentemente de sua denominação, sejam caracterizados como valores mobiliários. O Colegiado ressaltou, por fim, que plataformas de negociação constituídas para negociar, ainda que de forma não exclusiva, valores mobiliários devem verificar se estão sujeitas à legislação brasileira e à regulação editada pela CVM. ${ }^{41}$
\end{abstract}

\title{
a) O Caso Munchee Inc.
}

Um importante caso, no qual ficam claras as diferenças entre securities tokens e utilities tokens é o ICO realizado pela Munchee Inc., recentemente julgado pelos tribunais norte-americanos. A CVM, em sua manifestação sobre o ICO da Niobium, aponta o caso como forma a demonstrar que os utilities tokens, a depender da forma como são ofertados, podem vir a ser considerados como securities tokens e, portanto, sujeitos a registro perante o órgão regulador.

A Munchee Inc. é uma empresa da Califórnia que criou um aplicativo para Iphone que permite que seus usuários publiquem fotografias e avaliações de refeições em restaurantes. A Munchee pretendia vender tokens ou moedas digitais, conhecidas como MUNs, os quais seriam integrados ao aplicativo e utilizados para transações, incluindo compra de anúncios,

\footnotetext{
${ }^{41}$ Comissão de Valores Mobiliários (CVM). Processo SEI 19957.010938/2017-13, Reg. no 0888/18. Relator SRE. Julgado em: 30 de janeiro de 2018. Disponível em <http://www.cvm.gov.br/decisoes/2018/20180130_R1.html> Acesso em 14 de out. de 2018
} 
redação de comentários e venda de alimentos, como forma de levantar cerca de 15 milhões de dólares. Depois de um período inicial de marketing, a Munchee lançou sua ICO em 31 de outubro de 2017, mas no dia seguinte, foi obrigada a encerrá-la devido a uma ordem da SEC. Ocorre que, ao aplicar o Howey Test, a SEC constatou que os MUNs deveriam ser caracterizados como valores mobiliários e, desta forma, a Munchee havia violado o Securities Act ao vendê-los ao público sem cumprir com os requisitos necessários de registro.

Neste caso, o que chama a atenção é o fato do White Paper caracterizar os MUNs como utilities tokens, tendo em vista que estes seriam utilizados no aplicativo desenvolvido com o investimento do $\mathrm{ICO}^{42}$. Entretanto, a SEC buscou demonstrar em sua decisão que apesar dos tokens serem utilizados no aplicativo, a divulgação da oferta criou a expectativa de que o valor dos MUNs aumentaria devido aos esforços da empresa em devolver sua aplicação, bem como que os investidores poderiam esperar obter lucro vendendo os seus MUNs através de um mercado secundário líquido. Desta forma, esses recursos alinham-se aos elementos centrais do Howey Test, quais sejam, a presença de um investimento em empreendimento comum, no qual há uma razoável expectativa de lucro decorrente dos esforços de terceiros $^{43}$.

\footnotetext{
42 "The white paper stated that "as currently designed, the sale of MUN utility tokens does not pose a significant risk of implicating federal securities laws." (ROBBINS, Robert. B; BUDOFSKY, Daniel N. Munchee ICO. Commission's action shows the limited utility of the utility token-security token distinction. Disponível em <https://www.pillsburylaw.com/en/news-and-insights/the-secsshutdown-of-the-munchee-ico.html> Acesso em 17 de out. de 2018)

43 "MUN token purchasers had a reasonable expectation of profits from their investment in the Munchee enterprise. The proceeds of the MUN token offering were intended to be used by Munchee to build an "ecosystem" that would create demand for MUN tokens and make MUN tokens more valuable. (...) Even if MUN tokens had a practical use at the time of the offering, it would not preclude the token from being a security. Determining whether a transaction involves a security does not turn on labelling - such as characterizing an ICO as involving a "utility token" - but instead requires an assessment of "the economic realities underlying a transaction." (...) All of the relevant facts and circumstances are considered in making that determination." (Estados Unidos da América. Securities Act of 1993 - Release No 10445 / December 11, 2017. Administrative Proceeding File. $\mathrm{N}^{\circ}$ 3-18304. in the matter of Munchee Inc. Order Instituting Cease-Anddesist Proceedings pursuant to Section 8A of the Securities Act of 1933, Making Findings, and Imposing a Cease-and-Desist Order.. Relator: Brent J. Fields, Secretary.. Disponível em <https://www.sec.gov/litigation/admin/2017/33-10445.pdf> Acesso em 17 de out. de 2018)
} 
A decisão neste caso atinge o centro da distinção entre um "utility token" e um "security token". O que se deve ter claro, e que foi analisado pela CVM no caso Niobium, conforme exposto acima, é a expectativa dos investidores de obterem lucros devido aos esforços de terceiro, no caso, o emissor. Isto é, sabemos que os utility tokens dão aos seus investidores direito a um serviço e assim, se estes serviços forem considerados remuneração, estaremos diante de um valor mobiliário propriamente dito.

\subsection{Os Debt Tokens}

No caso dos debt tokens, tendo em vista que estes representam apenas um empréstimo a curto prazo, isto é, por não oferecem qualquer direito por si só, sendo utilizados unicamente como meio de troca, ao aplicarmos o Howey Test, resta claro que em sua oferta não é oferecido aos investidores qualquer remuneração que tenha origem nos esforços do empreendedor ou de terceiros.

Desta forma, nos resta a análise dos equity tokens, na medida que estes podem ser considerados como valores mobiliários, conforme será demonstrado, bem como a possibilidade jurídica da realização dos ICOs considerando o arcabouço regulatório vigente. 


\section{CAPÍTULO 4 -OS INITIAL COIN OFFERINGS E A ATUAL REGULAMENTAÇÃO DO BRASIL}

Conforme mencionado acima, a depender do contexto econômico de sua emissão e dos direitos conferidos aos investidores, os ICOs podem ser configurados como ofertas de valores mobiliários. O presente capítulo propõe a análise de ofertas de equity tokens, buscando demonstrar como esta configuraria uma oferta de valores mobiliários e que, nestes termos, deveria atrair a competência da CVM em sua análise.

Em um segundo momento, analisaremos a atual regulamentação do mercado de capitais, buscando identificar um possível panorama regulatório no qual os ICOs poderiam se adequar, bem como sugerir possíveis alterações a estas disposições como forma a viabilizar as ofertas de criptomoedas.

\subsection{Equity Tokens e os Initial Coin Offerings}

Os equity tokens refletem certo tipo de participação na entidade que os estão emitindo, sendo muito similar às ações de empresas comercializadas em bolsas de valores. Atualmente, é um dos meios mais comuns para financiar projetos de start-ups e fintechs, por permitir um meio de capitalização eficaz e alheio às burocracias do mercado de capitais e do mercado financeiro. Estes tokens podem garantir desde o direito a divisão de lucros decorrentes da utilização de determinada plataforma blockchain até mesmo, a participação societária nas start-ups que desenvolvem o projeto.

Ao conferir direito de participação, muitas vezes conferindo também direito de voto conduzido através do sistema de blockchain, não há dúvidas que este título deve ser configurado como valor mobiliário. Buscando expor este entendimento, utilizaremos como parâmetro dois casos analisados pela CVM, quais sejam as ofertas do HashBrasil e Hashcoin Brasil, nos quais a CVM se manifestou por meio de "stop orders", devido a configuração dos 
títulos distribuídos como contratos de investimento coletivo, nos termos do inciso IX do Art. $2^{\circ}$ da Lei 6.385.

\section{a) Oferta Irregular de Valores Mobiliários - Análise da oferta HashBrasil e Hashcoin Brasil}

No final de 2017, a empresa Hashcoin Brasil realizou uma oferta de criptomoedas em seu site, por meio do qual, convocava interessados em comprar cotas de investimento para financiamento do processo de criação de bitcoins, conhecido como mineração. No site, a empresa diz que, ao comprar uma cota, o investidor "passa a receber bitcoins diariamente provenientes da mineração correspondente ao poder de processamento de suas cotas" ${ }^{44}$.

A CVM, em sua função fiscalizatória, iniciou a análise do conteúdo divulgado no site da empresa. Com base no divulgado, foi enviado ofício ao ofertante buscando esclarecer se o investimento poderia ser enquadrado no conceito de contrato coletivo presente no ordenamento jurídico e pedindo maiores informações sobre a oferta. Em resposta, a Hashcoin Brasil restringiu-se a esclarecer que “(...) não há como imputar a prática punitiva, pois a empresa trabalha com contrato de uso de software, não com operações

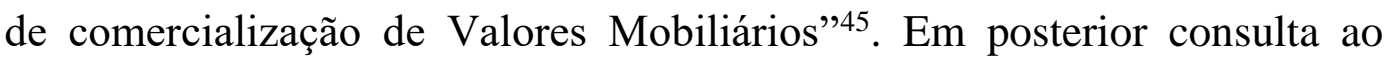
Ministério Público, ambos entenderam pertinente à emissão de stop order para a oferta, tendo em vista que o modelo de negócio conferido ao público constituiria oferta pública irregular de valores mobiliários.

\footnotetext{
44 FOLHAPRESS. Operação para ofertar bitcoins é suspensa. Disponível em <https://www.folhape.com.br/economia/economia/economia/2017/12/21/NWS,52967,10,550,ECO NOMIA,2373-OPERACAO-PARA-OFERTAR-BITCOINS-SUSPENSA.aspx>Acesso em 28 de set. de 2018.

45 Comissão de Valores Mobiliários (CVM). Processo n ${ }^{\circ} 19957.011454 / 2017-91$. Memorando $n^{\circ}$ 17/2017-CVM/SRE. Relator Dov Rawet - Superintendente de Registro de Valores Mobiliários. Emitido em: 18 de dezembro de 2017. Disponível em < http://www.cvm.gov.br/export/sites/cvm/decisoes/anexos/2017/20171219/0882.pdf> Acesso em 28 de set. de 2018.
} 
Em sua análise, a CVM utilizou o Howey Test como forma a verificar a configuração do token oferecido como valor mobiliário ${ }^{46}$. Os três primeiros pontos são de fácil análise, uma vez que (i) os investidores aplicariam recursos financeiros para adquirir cotas; (ii) por meio do aceite ao contrato com termos e condições de uso que foi disponibilizado; (iii) sendo este um investimento oferecido e adquirido indistintamente pelo público.

Além disso, de acordo com o entendimento da CVM, informações presentes no site onde a oferta fora divulgada, tais como "para cada $\mathrm{R} \$$ 100,00 investido existe um retorno esperado de $\mathrm{R} \$ 280,00$ em um ano, ou seja, $180 \%$ a.a. de rentabilidade", representariam uma promessa de remuneração aos seus investidores provenientes dos esforços do empreendedor. Trechos como "Trabalhamos com BITCOIN há muito tempo e conhecemos as melhores formas de investir em mineração. Desta forma resolvemos toda parte técnica do processo de mineração livrando assim os investidores de ter que se preocupar com esse tipo de detalhes, ficando os mesmo atentos apenas aos Bitcoins minerados" e "A HashCoinBrasil cobra apenas as taxas de luz (manutenção das mineradoras) e comissão de $20 \%$ para as operações" corroboraram o entendimento, levando a CVM a concluir pela configuração destes tokens como valores mobiliários, uma vez identificados todos os requisitos do Howey Test.

Com isto, a CVM editou em 19 de dezembro de 2017 a Deliberação $\mathrm{CVM} \mathrm{n}^{\circ} 785$, na qual suspende a referida oferta tendo em vista que os tokens oferecidos enquadram-se no conceito de valor mobiliário e a oferta não foi objeto de registo junto à autarquia ${ }^{47}$. Em 28 de fevereiro de 2018, nestes

\footnotetext{
46 "Como existe investimento, como o investimento está formalizado em contrato, como o investimento é coletivo, como foi oferecida remuneração aos investidores, como a remuneração tem origem no esforço do empreendedor ou de terceiros e como o contrato foi oferecido publicamente, a oferta HashCoin Brasil constitui contrato de investimento coletivo previsto no inciso IX, do art. $2^{\circ}$ da Lei ${ }^{\circ} 6.385 / 76$, sendo portanto, valor mobiliário.” (Ibid. p. 2)

47 “(...) nem o ofertante, tampouco a oferta pública de valor mobiliário, cuja divulgação vem sendo realizada, foram submetidos a registro ou dispensa de registro perante a CVM, o que configura infração aos artigos 19 , inciso I, do $\S 5^{\circ}$ do art. 19 da Lei $n^{\circ} 6.385 / 76$ e 21 , $\S 1^{\circ}$, da Lei $n^{\circ} 6.385$, de 7 de dezembro de 1976 , e $4^{\circ}, \S 1^{\circ}$, da Lei ${ }^{\circ} 6.404$, de 15 de dezembro de 1976; e d. a oferta pública de valores mobiliários sem prévio registro ou dispensa de registro na CVM autoriza esta Autarquia a determinar a suspensão de tal procedimento, na forma do art. 20 da Lei $n^{\circ} 6.385$, de 7 de dezembro de 1976, sem prejuízo das sanções administrativas cabíveis, e constitui, ainda e em tese, o crime
} 
mesmos termos, a CVM novamente se manifestou e suspendeu a oferta da HashBrasil, utilizando como base os mesmos argumentos expostos anteriormente ${ }^{48}$.

No atual ordenamento jurídico brasileiro, até a presente data, não há leis específicas tratando de ofertas de criptomoedas. O que já temos, são análises de casos concretos realizadas pela CVM. Sendo assim, conduzir uma ICO ainda é uma atividade inerente de segurança jurídica e somente uma análise específica, caso a caso, permitirá uma avaliação segura dos riscos e implicações desta prática.

\subsection{Initial Coin Offering (ICO) vs. Initial Public Offering (IPO)}

Tanto os ICOs como os IPOs são utilizados como meios de captação pública de recursos, funcionando como alternativas a modalidades privadas de captação como empréstimos bancários e financiamentos diretos. Além disso, ao compararmos os direitos dos titulares de equity tokens e aqueles decorrentes das ações distribuídas em um IPO, torna-se inevitável a comparação entre estas ofertas. Para tal comparação, é necessária uma breve exposição sobre o procedimento dos IPOs, de acordo com a regulamentação brasileira.

A oferta pública inicial de ações, conhecida como IPO, é a operação pela qual a companhia, previamente registrada na CVM, promove a colocação de suas ações no mercado e os investidores interessados em se tornarem titulares desses valores mobiliários, devem subscrevê-los e o preço por eles pago será revertido para o ofertante.

previsto no art. $7^{\circ}$, inciso II, da Lei ${ }^{\circ}$ 7.492, de 16 de junho de 1986;" (Comissão de Valores Mobiliários (CVM). Deliberação CVM n 785, de 19 de dezembro de 2017. Disponível em <http://www.cvm.gov.br/export/sites/cvm/legislacao/deliberacoes/anexos/0700/deli785.pdf〉 Acesso em 28 de set. de 2018)

${ }^{48}$ Comissão de Valores Mobiliários (CVM). Deliberação CVM no 790, de 28 de fevereiro de 2018. Disponível 
Os IPOs podem ser realizados no Brasil seguindo o procedimento da Instrução CVM no 400 de 29 de dezembro de 2003 ou da Instrução CVM n 476 de 16 de janeiro de 2009. Conforme será demonstrado abaixo, a comparação entre IPO e ICO só será possível quando tratarmos das ofertas públicas realizadas nos termos da Instrução CVM nº 400.

\section{a) Oferta Pública com Esforços Restritos (Instrução CVM no 476)}

Considerando que os investidores profissionais não precisariam da proteção concedida pela análise da CVM, e como forma a permitir que as companhias busquem crédito via mercado de capitais de forma mais rápida e sujeitas a exigências mais brandas que as da Instrução CVM n ${ }^{\circ} 400$, a Instrução CVM n 476 passou a viabilizar ofertas públicas dispensadas automaticamente do registro exigido pelo caput do artigo 19 da Lei 6.385. As ofertas públicas com esforços restritos, como são conhecidas, de acordo com o disposto no art. $2^{\circ}$ da Instrução CVM n ${ }^{\circ} 476$, são aquelas destinadas exclusivamente a investidores profissionais, conforme definidos na Instrução CVM no 539 de 13 de novembro de 2013 (Art. $9^{\circ}-\mathrm{A}^{49}$ ), e devem observar diversas limitações se comparadas com as ofertas realizadas via Instrução $\mathrm{CVM} \mathrm{n}^{\circ} 400$.

Em sua edição, a Instrução CVM n 476 restringia as hipóteses de realização de ofertas públicas com esforços restritos a títulos de dívidas, tais

\footnotetext{
${ }^{49}$ Art. $9^{\circ}$-A São considerados investidores profissionais:

I - instituições financeiras e demais instituições autorizadas a funcionar pelo Banco Central;

II - companhias seguradoras e sociedades de capitalização;

III - entidades abertas e fechadas de previdência complementar;

IV - pessoas naturais ou jurídicas que possuam investimentos financeiros em valor superior a $\mathrm{R} \$$ 10.000.000,00 (dez milhões de reais) e que, adicionalmente, atestem por escrito sua condição de investidor profissional mediante termo próprio, de acordo com o Anexo 9-A;

$\mathrm{V}$ - fundos de investimento;

VI - clubes de investimento, desde que tenham a carteira gerida por administrador de carteira de valores mobiliários autorizado pela CVM;

VII - agentes autônomos de investimento, administradores de carteira, analistas e consultores de valores mobiliários autorizados pela CVM, em relação a seus recursos próprios;

VIII - investidores não residentes.
} 
como debêntures e notas promissórias, sem criar qualquer diferenciação entre o emissor, garantindo que tanto companhias abertas como companhias fechadas pudessem realizar ofertas nestes termos. Com as alterações propostas pela Instrução CVM n 551 de 25 de setembro de 2014, tornou-se possível a realização de oferta pública de ações com esforços restritos, ou seja, com dispensa automática de registro de distribuição da oferta pela CVM, nos termos da Instrução CVM n ${ }^{\circ} 476^{50}$. Até a presente data, não se tem conhecimento de qualquer oferta inicial de ações realizada de acordo com a Instrução CVM n ${ }^{\circ} 476$, entretanto, considerando a possibilidade jurídica, nos resta a análise conceitual exposta abaixo.

Além da necessidade dos valores mobiliários serem ofertados unicamente para "investidores profissionais", no que diz respeito aos outros requisitos específicos para a realização de uma oferta via Instrução CVM n 476, podemos destacar a necessidade de distribuição com esforços restritos de colocação e distribuição, tendo em vista que será permitida a procura de, no máximo, 75 investidores profissionais, e os valores mobiliários deverão ser subscritos ou adquiridos por, no máximo, 50 investidores profissionais (Art. $3^{\text {o51}}$ ), mitigando-se os riscos de uma distribuição muito ampla e para investidores mais vulneráveis aos riscos inerentes a uma oferta sem registro na CVM. Neste primeiro ponto, resta clara a impossibilidade de realização

\footnotetext{
50 Art. $1^{\circ}$ Serão regidas pela presente Instrução, as ofertas públicas de valores mobiliários distribuídas com esforços restritos.

$\S 1^{\circ}$ Esta Instrução se aplica exclusivamente às ofertas públicas de:

(...)

$\mathrm{X}$ - certificados de operações estruturadas;

$\mathrm{XI}$ - os seguintes valores mobiliários, desde que emitidos por emissor registrado na categoria A:

a) ações;

b) debêntures conversíveis por ações; e

c) bônus de subscrição, mesmo que atribuídos como vantagem adicional aos subscritores de debêntures;

XII - debêntures permutáveis por ações, desde que tais ações sejam emitidas por emissor registrado na categoria $\mathrm{A}$;

XIII - certificados de depósito de valores mobiliários mencionados neste parágrafo; e

XIV - certificados de depósito de valores mobiliários no âmbito de Programa BDR Patrocinado Nível III. (Incisos X a XIV incluídos pela Instrução CVM nº 551, de 25 de setembro de 2014.)

${ }^{51}$ Art. $3^{\circ}$ Nas ofertas públicas distribuídas com esforços restritos:

I - será permitida a procura de, no máximo, 75 (setenta e cinco) investidores profissionais, conforme definido em regulamentação específica; e

II - os valores mobiliários ofertados deverão ser subscritos ou adquiridos por, no máximo, 50 (cinquenta) investidores profissionais.
} 
de um ICO via Instrução CVM no 476, tendo em vista a ampla divulgação do White Paper e acesso ilimitado pelos investidores.

A regra também dispõe que não será permitida a busca de investidores através de lojas, escritórios ou estabelecimentos abertos ao público, ou com a utilização de serviços públicos de comunicação, como a imprensa, o rádio, a televisão e páginas abertas ao público na rede mundial de computadores (Art. $2^{\circ}$, parágrafo único ${ }^{52}$ ), o que, conforme exposto no capítulo acima, é a principal forma de divulgação de um ICO.

Nos resta dizer que nas ofertas públicas com esforços restritos não há qualquer documento com o qual poderíamos comparar o conteúdo dos White Papers, bem como essas operações exigem elevados padrões de diligência da instituição intermediária líder da oferta, para garantir que quaisquer informações prestadas aos investidores sejam verdadeiras, consistentes, corretas e suficientes para uma decisão fundamentada de investimento, o que não ocorre no caso dos ICOs. Concluímos então pela impossibilidade de realização de um ICO de acordo com a atual regulamentação da Instrução CVM n ${ }^{\circ} 476$, tendo em vista as limitações previstas nesta.

\section{b) Oferta Pública de Valores Mobiliários (Instrução CVM no 400)}

A forma mais comum para realização de uma oferta pública de ações ocorre através da Instrução CVM n ${ }^{\circ} 400$, a qual regula as ofertas públicas de distribuição de valores mobiliários em geral e busca proteger os interesses dos investidores e do mercado através da imposição de um tratamento equitativo aos ofertados por meio de ampla, transparente e adequada divulgação de informações sobre a oferta, o emissor dos valores mobiliários, o ofertante e os valores mobiliários ofertados.

\footnotetext{
${ }^{52}$ Art. $2^{\circ}$ (...) Parágrafo único. Não será permitida a busca de investidores através de lojas, escritórios ou estabelecimentos abertos ao público, ou com a utilização de serviços públicos de comunicação, como a imprensa, o rádio, a televisão e páginas abertas ao público na rede mundial de computadores.
} 
As ofertas públicas realizadas nos termos da Instrução CVM no 400 são direcionadas ao público em geral e, portanto, atingem um número maior de investidores, também chamados de "investidores de varejo", que incluem pessoas físicas comuns usualmente sem experiência específica em investimento em valores mobiliários, fazendo com que haja uma maior preocupação da CVM com a proteção ao investidor. Como forma a viabilizar esta proteção e, por outro lado, permitir o acesso das companhias ao mercado de capitais, a tutela estatal dá-se basicamente a partir de uma política de disclosure de divulgação de informação.

Para que a companhia se torne uma sociedade por ações de capital aberto apta a realizar a oferta pública de distribuição de valores mobiliários pretendida deverá obter registro de emissor perante a CVM. Este pedido é distinto do processo de registro da oferta propriamente dito, e deverá ser realizado de acordo com a Instrução CVM n ${ }^{\circ} 480$, que dispõe sobre os requisitos necessários para que a companhia mantenha um nível informacional suficiente para que toda a informação necessária para o completo e correto conhecimento do emissor em todos os seus aspectos relevantes seja divulgada ao mercado.

Além do registro de companhia aberta, é necessário o registro da oferta de valores mobiliário junto à CVM, o qual compreende informações específicas sobre os valores mobiliários distribuídos e a oferta pública em si.

\section{c) A Inevitável Comparação}

Buscando restringir o escopo proposto no presente trabalho, abordaremos abaixo as principais características de uma oferta pública de ações realizada nos termos da Instrução CVM n 400 buscando compará-la com o procedimento de um ICO. Acreditamos que, nos termos da atual regulamentação, exceto pelo previsto no item (d), não seria possível a condução de um ICO, entretanto, o proposto aqui é uma comparação, 
buscando discutir eventuais adaptações tanto da Instrução da CVM como no procedimento dos ICOs, a fim de viabilizá-los.

\section{c.1) Supervisão Regulatória}

O Anexo II da Instrução CVM nº 400 lista os documentos necessários para apresentação à CVM no momento do pedido de registro entre os quais, destaca-se, o prospecto da oferta. Neste documento, conforme dispõe a referida instrução (Art. 38), o ofertante, em conjunto com a instituição líder responsável pela distribuição, deverá apresentar “(...) informação completa, precisa, verdadeira, atual, clara, objetiva e necessária, em linguagem acessível, de modo que os investidores possam formar criteriosamente a sua decisão de investimento". Como forma a uniformizar a informações básicas constantes deste documento, o Art. 39 aponta:

\footnotetext{
Art. 39. O Prospecto deverá, de maneira que não omita fatos de relevo, nem contenha informações que possam induzir em erro os investidores, conter os dados e informações sobre:

I - a oferta;

II - os valores mobiliários objeto da oferta e os direitos que lhes são inerentes;

III - o ofertante;

IV - a companhia emissora e sua situação patrimonial, econômica e financeira;

$\mathrm{V}$ - terceiros garantidores de obrigações relacionadas com os valores mobiliários objeto da oferta; e

VI - terceiros que venham a ser destinatários dos recursos captados com a oferta.
}

A comparação com os White Papers torna-se possível ao verificarmos que o prospecto, assim como o documento apresentado aos investidores em um ICO, representa uma declaração legal da ofertante da sua intenção de emitir suas ações ao público, de modo a ajudar os potenciais investidores na tomada de uma decisão informada. Ocorre que, diferente do disposto na Instrução CVM n ${ }^{\circ} 400$, os ICOs não estão vinculados a quaisquer requisitos legais para emitir sua documentação legal.

O conteúdo dos White Papers é muitas vezes concebido pela equipe de desenvolvimento para delinear as principais informações do projeto, tais 
como a sua finalidade e mecânica e não há um padrão para um documento técnico. Desta forma, devido à falta de regulamentação específica em relação ao conteúdo dos White Papers, para que estes pudessem ser comparados com os prospectos, de acordo com a regulamentação vigente, deveriam observar certos padrões mínimos, tais como os requisitos listados no Anexo III da Instrução CVM nº 400, conforme aplicáveis ${ }^{53}$.

\section{c.2) Histórico e Credibilidade}

Durante o processo de registro da oferta na CVM, a autarquia pode apresentar diversas exigências relacionadas tanto a oferta como ao ofertante, buscando garantir a proteção ao investidor que todas as informações necessárias ao investimento estão disponíveis. Estes processos funcionam como um filtro natural para as companhias emitirem suas ações ao público.

Nos ICOs, não observamos essa preocupação em relação ao histórico e credibilidade da ofertante, uma vez que, como não há qualquer requisito necessário para adesão dos ofertantes, como ocorre no caso do registro da companhia em um IPO, a maioria deles não têm um histórico e apresentam apenas as informações constantes no White Paper relacionados ao seu projeto. Assim, diferentemente do que ocorre em um IPO, no qual a CVM

\footnotetext{
${ }^{53}$ Apenas a título de exemplo, indicamos:

(...)

1.5. Descrição dos direitos atribuídos e das principais características dos valores mobiliários ofertados, individualizadas por classes e séries, se for o caso, e abrangendo, em particular:

1.5.1. identificação da rentabilidade assegurada ou prevista;

1.5.2. condições para emissão, negociação, amortização e resgate dos valores mobiliários;

1.5.3. divulgação do cronograma previsto para distribuição de recursos aos titulares dos valores mobiliários ofertados, mediante amortização ou resgate, por classe, com descrição das prioridades de pagamento e respectivas alocações por classe de valores mobiliários emitidos.

1.5.4. informação sobre requisitos ou exigências mínimas de investimento, caso existam, bem como sobre eventuais restrições à transferência de cotas.;

(...)

Os fatores de risco, conforme constam na seção 3 do Anexo III, também poderiam tornar-se exigência nos White Papers, considerando todo o risco envolvido nessa operação:

3.1. Riscos decorrentes dos critérios adotados pelo originador ou cedente para concessão de crédito. 3.2. Riscos decorrentes dos negócios e da situação patrimonial e financeira do devedor ou coobrigado enquadrado nas hipóteses previstas nos itens 5.2 e 5.3 deste Anexo. (...)

3.7. Quaisquer outros riscos decorrentes da estrutura da operação e das características e da natureza dos direitos creditórios e demais ativos que integrarão o patrimônio do ofertante
} 
pode contar com informações dos ofertantes, provenientes de seu registro prévio, sua diligência em relação aos ICO é prejudicada, vez que pode contar apenas com as expectativas futuras do projeto descritas no White Paper.

Deste fato decorre grande parte do risco do investimento em ICOs. Apesar da possível avaliação do histórico e experiência dos desenvolvedores do projeto conforme descrito no White Paper apresentar certa credibilidade, o registro e diligência da CVM nos IPOs garantem um grau muito maior de conforto aos seus investidores. Conforme exposto acima, a grande preocupação da CVM, na edição da Instrução CVM no 400, é garantir a proteção dos investidores por meio de ampla divulgação de informações corretas, verdadeiras e que não o induzam ao erro, o que não verificamos atualmente no procedimento de um ICO. A fim de viabilizá-lo, poderíamos sugerir uma possível modificação na referida instrução com a inclusão de uma análise prévia pela CVM dos desenvolvedores ou, até mesmo, a criação de um procedimento de registro diferenciado para estes nos termos da Instrução CVM nº 480.

\section{c.3) Utilidade}

Conforme citado acima, o procedimento de um IPO resulta na distribuição de ações de uma companhia, as quais representarão aos seus titulares, denominados acionistas, uma parcela de participação em seu capital social. As ações adquiridas podem apresentar diversas classes, como ações ordinárias, preferenciais e de fruição e atribuirão aos acionistas direitos patrimoniais e políticos, sendo estes classificados de acordo com o benefício oferecido. Podemos citar, a título de exemplo, como direitos patrimoniais, o direito ao dividendo, à quota de liquidação, de preferência em aumento de capital e, como direitos políticos, o direito de voto, de participação em assembleia, entre outros.

Desta forma, ao contrário de um IPO, a aquisição de criptomoedas não concede a seus titulares a propriedade do projeto. Há muitas maneiras que os 
investidores das criptomoedas podem colher benefícios futuros a depender da forma como os tokens distribuídos foram estruturados, conforme exposto acima, entretanto, não é possível afirmar que em um ICO o investidor, ao adquirir criptomoedas, torna-se titular de parte do projeto financiado. Geralmente, o valor de uma criptomoeda está diretamente ligado com a sua utilidade percebida, na medida que tokens podem conferir apenas uma participação na receita futura dos projetos e outros permitirem apenas o seu uso dentro do sistema.

Isto é, não há qualquer uniformização em relação aos tokens objeto de distribuição via ICO, devendo o investidor analisar cautelosamente o conteúdo do White Paper de forma a estar ciente dos direitos adquiridos com o investimento. É neste ponto também que a CVM deve-se manter atenta, de modo a verificar a possível necessidade de sua supervisão.

\section{c.4) Duração das Ofertas}

A duração das ofertas também apresenta uma grande diferença. Atualmente, uma emissão tradicional de IPO pode durar entre 4 a 6 meses, devido ao processo de elaboração e análise dos documentos da oferta, período de investimento, bem como exigências formuladas pela CVM no trâmite do processo de registro. Ao compararmos com o processo de um ICO, o qual sua duração depende apenas da natureza e cronograma do projeto em si, verificamos que este pode ser realizado em um curto espaço de tempo, uma vez que depende apenas da emissão de seu White Paper e finalização do crowdsale, o que geralmente leva um mês para sua concretização.

\section{c.5) Investidores}

Apesar da Instrução CVM nº 400 não criar restrições aos investidores da oferta, de forma que esta é destinada também a investidores de varejo, como são conhecidos, na prática, ao final de uma oferta inicial de ações, 
verificamos que a maior parte dos valores distribuídos se encontram com bancos de investimento, fundos, isto é, entre investidores profissionais. Apenas pequena parcela é alocado aos investidores de varejo. Em um ICO, devido ao fácil acesso ao investimento e ampla divulgação da oferta, há grande participação de pessoas físicas, investidores estes muitas vezes sem qualquer experiência prévia.

Esta diferenciação decorre do fato que, enquanto em um IPO as ações são negociadas em bolsa de valores, exigindo um certo trâmite ao seu investidor para registro e aquisição, em um ICO é necessário apenas a aquisição online de criptomoedas que serão posteriormente convertidas no token objeto do ICO. Com isto, verificamos uma maior participação dos investidores de varejo nessas ofertas, tornando possível uma maior diversificação na participação destes em financiamentos privados, fato para o qual a CVM deve atentar-se buscando garantir a proteção destes investidores.

\section{d) Uma Possível solução para a realização de ICOs via Instrução CVM no 400}

Nos atuais termos da Instrução CVM n 400, uma possível saída para os ICOs está prevista no Art. $4^{\circ}$ da Instrução CVM no 400, o qual elenca hipóteses de dispensa do registro da oferta ou de requisitos exigidos ${ }^{54}$.

\footnotetext{
${ }^{54}$ Art. $4^{\circ}$ Considerando as características da oferta pública de distribuição de valores mobiliários, a CVM poderá, a seu critério e sempre observados o interesse público, a adequada informação e a proteção ao investidor, dispensar o registro ou alguns dos requisitos, inclusive divulgações, prazos e procedimentos previstos nesta Instrução.

$\S 1^{\circ} \mathrm{Na}$ dispensa mencionada no caput, a CVM considerará, cumulativa ou isoladamente, as seguintes condições especiais da operação pretendida:

I - REVOGADO

II - o valor unitário dos valores mobiliários ofertados ou o valor total da oferta;

III - o plano de distribuição dos valores mobiliários (art. 33, § $3^{\circ}$ );

IV - a distribuição se realizar em mais de uma jurisdição, de forma a compatibilizar os diferentes procedimentos envolvidos, desde que assegurada, no mínimo, a igualdade de condições com os investidores locais;

$\mathrm{V}$ - características da oferta de permuta;

VI - o público destinatário da oferta, inclusive quanto à sua localidade geográfica ou quantidade; ou VII - ser dirigida exclusivamente a investidores qualificados.
} 
Desta forma, no início do procedimento do ICO, seus desenvolvedores poderão apresentar pedido de dispensa à CVM, elencando neste as peculiaridades da oferta bem como o público a qual se destina. Caso o pedido seja deferido, a análise da oferta terá um prazo diferenciado bem como a CVM poderá apresentar restrições à negociação dos valores mobiliários em mercado.

Isto é, considerando as diferenças indicadas entre o procedimento de um ICO e as disposições da Instrução CVM n 400, esta pode ser uma saída para realização de ICOs sujeitos a registro na autarquia. Para tanto, cabe aos desenvolvedores apresentarem argumentos suficientes para que a CVM entenda pela dispensa do registro. Neste ponto, cabe ressaltar que ainda seria necessário o registro do emissor, nos termos da Instrução CVM nº 480.

\subsection{Initial Coin Offering (ICO) vs. Crowdfunding}

$\S 2^{\circ}$ O pedido de dispensa de registro ou de requisitos do registro será formulado pelo ofertante, e pela instituição intermediária, se for o caso, em documento fundamentado, nos termos do Anexo I, que conterá as justificativas identificadas pelos requerentes para a concessão da dispensa, aplicandose na análise os prazos previstos nos arts. $8^{\circ}$ e $9^{\circ}$.

$\S 3^{\circ}$ Fica facultada a apresentação do pedido de registro de distribuição conjunta e simultaneamente ao pedido de dispensa de requisitos de registro.

$\S 4^{\circ}$ Na hipótese de dispensa de requisitos de registro com base no inciso VII do $\S 1^{\circ}$, deverá ser, adicionalmente, observado o seguinte:

I - o ofertante apresentará à CVM, juntamente com o pedido fundamentado mencionado no $\S 2^{\circ}$ deste artigo, modelo de declaração a ser firmado pelos subscritores ou adquirentes, conforme o caso, da qual deverá constar, obrigatoriamente, que:

a) têm conhecimento e experiência em finanças e negócios suficientes para avaliar os riscos e o conteúdo da oferta e que são capazes de assumir tais riscos;

b) tiveram amplo acesso às informações que julgaram necessárias e suficientes para a decisão de investimento, notadamente aquelas normalmente fornecidas no Prospecto; e

c) têm conhecimento de que se trata de hipótese de dispensa de registro ou de requisitos, conforme o caso;

II - todos os subscritores ou adquirentes dos valores mobiliários ofertados firmarão as declarações indicadas no inciso I deste parágrafo, as quais deverão ser inseridas nos boletins de subscrição ou recibos de aquisição, ou no termo de adesão e ciência de risco, no caso de oferta de cotas de emissão de fundos de investimento; e

III - REVOGADO

IV - sem prejuízo do disposto nos arts. $8^{\circ}$ e $9^{\circ}$, serão aplicados os seguintes prazos:

a) prazo de análise: $10(\mathrm{dez})$ dias úteis;

b) prazo de cumprimento de exigências: 10 (dez) dias úteis; e

c) prazo de verificação do cumprimento de exigências: 5 (cinco) dias úteis.

$\S 5^{\circ}$ Nas hipóteses de dispensa de registro ou de requisitos previstas neste artigo, a CVM pode impor restrições à negociação dos valores mobiliários em mercados regulamentados. 
Apesar da inevitável comparação entre o ICO e o IPO, entendemos que o atual procedimento de um ICO apresenta características mais próximas do financiamento coletivo conhecido como Equity Crowdfunding, regulamentado pela Instrução CVM no 588 de 13 de julho de 2017.

O Crowdfunding consiste em um financiamento coletivo, como o próprio nome sugere, pelo qual diversos participantes podem investir pequenas quantias em um projeto ou empreendimento, por meio de plataformas eletrônicas. O Banco Mundial, em 2013, apresentou a seguinte definição para a prática:

Crowdfunding é um meio por meio do qual, usando a internet, empresas ou outras organizações arrecadam dinheiro, sob a forma de doações ou investimentos, de vários indivíduos. Essa nova forma de arrecadação de capital surgiu de maneira organizada na sequência da crise financeira de 2008 , em grande parte em razão das dificuldades enfrentadas pelos artesãos, empresários e empresas em fase inicial de captação de recursos. Com os bancos tradicionais menos dispostos a emprestar, os empresários começaram a procurar em outro lugar o capital. ${ }^{55}$ (tradução livre)

Isto é, diante dos altos custos envolvidos em operações de mercado de capitais, bem como os procedimentos estabelecidos pela CVM para realização de uma oferta, o crowdfunding surge como uma opção de arrecadação de fundo para que pequenos projetos e empreendimentos, tais como start-ups, possam viabilizar as suas atividades por meio de investimento direto proveniente do público em geral.

De acordo com Cesar Augusto Rodrigues de Carvalho ${ }^{56}$, existem, atualmente, quatro modalidade conhecidas de crowdfunding, a saber (a) o crowdfunding não financeiro (a.1) mediante doação, em que os participantes doam recursos à sociedade financiada e não recebem qualquer contrapartida em razão da transferência ao ente financiado; ou (a.2) mediante recompensa,

\footnotetext{
${ }^{55}$ WORLD BANK, infoDev, Finance and Private Sector Development Department. Crowdfunding 's Potential for the Developing World. Washington, DC. 2013. p. 8. Disponível em <http://documents.worldbank.org/curated/pt/409841468327411701/pdf/840000WP0Box380crowd funding0study00.pdf> Acesso em 05 de nov. de 2018.

${ }^{56}$ CARVALHO, Cesar Augusto Rodrigues de. Equity crowdfunding: Regime Jurídico e sua Nova Regulamentação. Revista de Direito Bancário e do Mercado de Capitais. v. 78/2017. Out - Dez / 2017. p. $48-50$.
} 
em que os participantes transferem recursos à empresa financiada a fim de receber dela, em contrapartida, prêmios, bens ou serviços por ela desenvolvidos; (b) o crowdfunding financeiro (b.1) mediante empréstimo, em que os participantes entregam recursos à sociedade financiada e, em contrapartida, recebem ao final do contrato o valor emprestado, acrescido de juros fixados; e (b.2) de capital (ou equity crowdfunding), por meio do qual os investidores aplicam recursos na sociedade financiada mediante a aquisição de ativos financeiros por ela emitidos, sendo remunerados, assim, pela valorização do ativo adquirido e pelos eventuais proventos que a titularidade desse ativo outorga a seu proprietário.

Atualmente, apenas o equity crowdfunding encontra-se disciplinado por meio da Instrução CVM no 588 , que estabelece parâmetros normativos para a realização da oferta pública de distribuição de valores mobiliários de emissão de sociedades empresárias de pequeno porte, com a dispensa de registro, por meio de plataforma eletrônica de investimento participativo. Isto é, a CVM entende que apesar desta forma de financiamento representar uma oferta de valores mobiliários, devido às peculiaridades identificadas bem como a necessidade de desenvolvimento da regulamentação buscando adequá-la às inovações tecnológicas, a autarquia buscou apresentar regras específicas para estes casos, abrindo uma exceção ao caput do artigo 19 da Lei 6.385, sem abrir mão da segurança jurídica necessária ${ }^{57}$.

Em resumo, de acordo com o artigo $3^{\circ}$ e seguintes da Instrução CVM $n^{\circ} 588$, para gozar da isenção de registro na CVM, é preciso que: (i) os valores mobiliários ofertados tenham sido emitidos apenas por sociedades empresárias de pequeno porte, entendendo-se como tais apenas aquelas cuja receita bruta no exercício anterior não tenha sido maior que $\mathrm{R} \$ 10.000 .000,00$

\footnotetext{
57 “Disso resulta que uma oferta feita pela Internet é sem dúvida uma oferta pública; aliás, feita por um meio de comunicação muito mais eficiente do que os previstos em 1976, quando a informática era uma ferramenta para poucos e nem se sonhava com existência e o alcance social da World Wide Web. Essa é uma das situações em que a CVM tem a competência para trazer para seu âmbito de atuação a emissão pública ofertada por meios eletrônicos, com base no parágrafo $5^{\circ}$, inc. I, do artigo 19." MATTOS FILHO, Ary Oswaldo. Direito dos valores mobiliários. Rio de Janeiro: Editora FGV, 2015. v. 1. t. 2. p. 316.
} 
(dez milhões de reais); (ii) a oferta tenha valor alvo máximo de captação limitado a $\mathrm{R} \$ 5.000 .000,00$ (cinco milhões de reais); (iii) a oferta tenha prazo de, no máximo, 180 (cento e oitenta) dias; (iv) cada investidor não invista no projeto mais do que $\mathrm{R} \$ 10.000,00$ (dez mil reais); (v) seja garantido ao investidor um período de desistência de, no mínimo, 7 (sete) dias contados a partir da confirmação de investimento; e (v) os recursos captados pela sociedade empresária de pequeno porte não sejam utilizados para fusão, incorporação, incorporação de ações e aquisição de participação em outras sociedades, aquisição de títulos, conversíveis ou não, e valores mobiliários de emissão de outras sociedades ou concessão de crédito a outras sociedades.

Além das características acima, o artigo $5^{\circ}$ dispõe que a distribuição dos valores mobiliários deverá necessariamente ser feita por meio de uma única plataforma eletrônica, a qual, por sua vez, está sujeita a registro na CVM e deve exigir o cumprimento de alguns deveres de disclosure de informações, como o oferecimento de informações sobre o emissor e sobre o projeto. Diferentemente do que ocorre nas ofertas públicas de valores mobiliários realizadas pela Instrução CVM nº 400, não há necessidade da elaboração de prospecto da oferta e demais documentos aplicáveis, tampouco se exige que as demonstrações financeiras sejam auditadas, devendo o ofertante observar as exigências específicas relacionadas à plataforma eletrônica.

Uma vez exposto o procedimento do crowdfunding em linhas gerais, bem como os motivos que levaram a CVM a editar a Instrução CVM nº 588, a comparação com o ICO torna-se necessária. Ambos são instrumentos de captação de recursos por meio ofertas públicas para o financiamento de projetos e negócios de terceiros, realizadas por meio de plataformas eletrônicas localizadas em ambientes virtuais e podem vir a ser considerados como ofertas públicas de valores mobiliários atípicos, na forma do art. $2^{\circ}$, IX, da Lei 6.835 . 
De acordo com o entendimento de Maurício Custódio Dourado ${ }^{58}$, devemos restringir a comparação do ICO ao crowdfunding financeiro, uma vez que, diferentemente do que ocorre no crowdfunding não financeiro, no qual os investidores nada recebem em troca do aporte realizado ou recebem apenas prêmios, recompensas, bens ou serviços, um ICO possui um caráter especulativo inato relacionado ao possível ganho de capital em decorrência da eventual valorização dos tokens adquiridos na oferta.

Assim, embora um ICO jamais possa ser enquadrado como crowdfunding não financeiro diante das razões descritas acima, eventualmente, o ICO poderá ser entendido como uma espécie de equity crowdfunding, caso seja realizado dentro dos limites da Instrução CVM n ${ }^{\circ}$ 588 e observe as exigências regulatórias desta, viabilizando desta forma a sua realização, sem a necessidade de registro da oferta e do emissor junto à CVM. O ponto que deve ser discutido é o necessário registro da plataforma eletrônica, conforme dispões a Instrução CVM nº 588.

${ }^{58}$ DOURADO, Maurício Custódio. A Sujeição do Initial Coin Offering (ICO) à Regulação do Mercado de Capitais no Brasil. Revista de Direito Bancário e do Mercado de Capitais. v. 79. Jan Mar / 2018. p. 86-87 


\section{CAPÍTULO 5 - OS INITIAL COIN OFFERINGS NAS DEMAIS JURISDIÇÕES}

Ao tratarem de ICOs, as agências reguladoras de diversos país vêm apresentando diferentes posições, sem que haja qualquer entendimento uniforme em relação ao tema a nível mundial. Enquanto a China e a Coréia do Sul, a título de exemplo, surpreenderam a todos com a proibição da realização de qualquer ICO dentro de seu território, a Suíça conta hoje com a cidade de ZUG, referência para empresas de blockchain e conhecida como Vale das Cripto, em alusão ao Vale do Silício, na qual registram-se inúmeras operações de ICO. Ademais, outros países ainda buscam firmar o seu entendimento em relação ao tema, conforme será demonstrado abaixo.

O tema é de grande importância uma vez que, na realização de um ICO, a legislação a ser observada, em tese, deve ser a da sede da ofertante e não aonde estão os investidores. No entanto, em um ICO realizado no exterior, caso seja publicamente oferecido e comercializado em outro país, os desenvolvedores deverão observar a regulamentação destes, principalmente se tratarmos de equity tokens, os quais podem vir a ser considerados como valores mobiliário, implicando na necessidade de obtenção de registro junto às autoridades responsáveis pela supervisão de valores mobiliários local ${ }^{59}$.

\subsection{Estados Unidos}

Os Estados Unidos apresentou seu primeiro entendimento sobre a realização de ICOs em julho de 2017, após a análise do famoso caso "The DAO”, a primeira Descentralized Autonomous Organization, termo utilizado para identificar uma organização autônoma descentralizada, digital, que existe e funciona com base em Smart Contracts. O ICO da The DAO,

\footnotetext{
${ }^{59}$ Para maiores informações sobre o tema, veja CAMPOS, Emília Malgueiro. Op. Cit. p.100
} 
realizado entre abril e maio de 2016, vendeu aproximadamente USD 150 milhões em tokens $D A O$, comprados pelos investidores com a criptomoeda conhecida como Ether, criptoativo da plataforma Etherum, onde foi programado o smart contract do ICO.

Os Tokens $D A O$ permitiam aos seus titulares participarem de votações e receberem remuneração provenientes do projeto $^{60}$. Além disso, após o período da oferta, os titulares dos tokens $D A O$ poderiam negociá-los no mercado secundário, ou seja, por exchanges de criptomoedas. Assim, após sua análise, a SEC decidiu que houve descumprimento da legislação (Act 1934), uma vez que os Tokens DAO são valores mobiliários e o ICO, neste caso, deveria ser objeto de registro e aprovação da SEC, uma vez que representava uma forma de investimento em dinheiro, com expectativa de lucro, derivada do esforço de terceiros, preenchendo, portanto, os requisitos do Howey Test:

\begin{abstract}
The investigation raised questions regarding the application of the U.S. federal securities laws to the offer and sale of DAO Tokens, including the threshold question whether DAO Tokens are securities. Based on the investigation, and under the facts presented, the Commission has determined that DAO Tokens are securities under the Securities Act of 1933 ("Securities Act") and the Securities Exchange Act of 1934 ("Exchange Act"). (...) This Report reiterates these fundamental principles of the U.S. federal securities laws and describes their applicability to a new paradigm - virtual organizations or capital raising entities that use distributed ledger or blockchain technology to facilitate capital raising and/or investment and the related offer and sale of securities. The automation of certain functions through this technology, "smart contracts," or computer code, does not remove conduct from the purview of the U.S. federal securities laws. ${ }^{61}$
\end{abstract}

A partir desse entendimento, a SEC vem utilizando o Howey Test na análise de todos os ICOs oferecidos aos investidores em seu território, o que

\footnotetext{
60 “A DAO Token granted the DAO Token holder certain voting and ownership rights. According to promotional materials, The DAO would earn profits by funding projects that would provide DAO Token holders a return on investment. The various promotional materials disseminated by Slock.it's co-founders touted that DAO Token holders would receive "rewards," which the White Paper defined as, "any [ETH] received by a DAO [Entity] generated from projects the DAO [Entity] funded." DAO Token holders would then vote to either use the rewards to fund new projects or to distribute the ETH to DAO Token holders." (Estados Unidos da América. Securities Act of 1934 Release No 81207 / July, 25, 2017. Report of Investigation Pursuant to Section 21(a) of the Securities Exchange Act of 1934: The DAO. <https://pt.scribd.com/document/354711758/SECReport\#download\&from_embed> Acesso em 06 de nov. de 2018)

${ }^{61}$ Ibid. p. 1-2.
} 
torna bastante restrita a aplicação da tecnologia para esse modelo de negócio nos Estados Unidos, principalmente para ofertas de security tokens.

No caso de utility tokens, estes também podem ser considerados valores mobiliários, de acordo com a SEC, caso configurem uma forma de investimento. Nesse sentido, se o ICO é referente a uma plataforma que ainda não é operacional e os tokens não poderão ser utilizados para obtenção de serviços pelos adquirentes logo após sua aquisição, essa tem característica de investimento e, portanto, deve atender as regras e ser autorizado pela SEC.

Até o presente momento, a SEC já emitiu algumas ordens de suspensão à ICOs por irregularidades, como foi o caso da The DAO, entre outros $^{62}$.

\subsection{China $x$ Hong Kong}

Apesar da prosperidade econômica, o mercado chinês é notavelmente controlado pelo governo, de forma que é fácil entender o motivo pelo qual estes seriam tão cautelosos ao tratar de um movimento econômico que promete liberdade descentralizada, como é o caso da tecnologia blockchain. Assim, em setembro de 2017, agências regulatórias chinesas emitiram uma declaração informando que as ICOs são uma forma ilegal de arrecadação de fundos e que todas as pessoas e empresas da República Popular da China estariam proibidas de lançar vendas de tokens para financiar seus empreendimentos.

No início de 2018, o governo chinês reafirmou o compromisso com a proibição, ao estabelecer o encerramento de todas as bolsas baseadas na China que não cumprirem as ordens anteriores de erradicar o comércio relacionado às criptomoedas. Pesquisas recentes demonstram que cidadãos

\footnotetext{
62 A título de exemplo, citamos as ofertas do First Bitcoin Capital Corp, CIAO Group, Strategic Global e Sunshine Capital.
} 
chineses continuam a participar de ICOs de maneira clandestina. A proibição reflete a postura de um governo central e de difícil acesso:

\begin{abstract}
Não apenas o mercado volátil da criptografia e da ICO poderia afetar severamente os cidadãos chineses, mas a ideologia por trás disso poderia minar seriamente uma estrutura governamental e social que foi construída em torno das ideias por trás do comunismo e de um sistema centralista. ${ }^{63}$
\end{abstract}

Ao contrário da China continental, Hong Kong, sendo um território autônomo, apresenta um sistema político separado do resto do país, o que também tem grande efeito em sua economia local. Assim, em 5 de setembro 2017, a Comissão de Valores Mobiliários e Futuros (SFC), órgão responsável pela regulamentação, publicou uma declaração que afirma que os tokens digitais que se enquadrarem na definição de títulos mobiliários poderão atuar respeitando as leis do mercado mobiliário de Hong Kong:

Blockchain is a very high priority for us. There is hype, and there is the fast grab of money with ICOs in some cases. But what we are looking at building here in Hong Kong is an infrastructure for new businesses and existing businesses, to make sure the technology and innovations remain a key enabler for financial sector growth. ${ }^{64}$

Em fevereiro de 2018, a SFC emitiu um segundo comunicado sobre os potenciais riscos de investir em ICOs, alertando os investidores a manterem a devida diligência. Desde então, o órgão regulador vem acompanhando de perto as emissões, emitindo stop orders e advertências, quando necessário.

\title{
5.3. Suíça
}

\footnotetext{
${ }^{63}$ RAZA, Ali. Analisando a proibição final da China em todos os sites de criptografia e ICO. Disponível em <https://cryptoslate.com/analyzing-chinas-ultimate-ban-crypto-ico-websites/> Acesso em 06 de nov de 2018.

${ }^{64}$ O'NEAL, Stephen. Hong Kong Continues Taking Regulatory Action, Hopes to Become International Blockchain Hub. Disponível em <https://cointelegraph.com/news/hong-kongcontinues-taking-regulatory-action-hopes-to-become-international-blockchain-hub> Acesso em 06 de nov. de 2018.
} 
Atualmente, a Suíça vem sendo indicada como referência quando o assunto são as criptomoedas. Nesse sentido, em 16 de fevereiro de 2018, a Autoridade Supervisora do Mercado Financeiro Suíco (FINMA), instituição independente do governo central da Suíça, mas com poder jurídico e que se reporta diretamente ao parlamento, publicou um conjunto de diretrizes a serem aplicados a legislação existente à regulamentação dos ICOs.

A instituição defende que essas normas são muito importantes e criam transparências num momento dinâmico desse novo mercado e de altas demandas ${ }^{65}$. $\mathrm{O}$ documento busca explicar, de forma didática, regras básicas que o investidor deve observar, como forma a ter maior segurança para seus investimentos, além de chamar a atenção de todos para os riscos associados aos ICO, ao tratarem da volatilidade dos preços do mercado e da natureza jurídica potencialmente incerta dos contratos feitos com a tecnologia blockchain. $\mathrm{O}$ documento explicita as três categorias de tokens com base na função econômica e na finalidade de cada um, quais sejam, os payment tokens, os utility tokens e os asset tokens, demonstrando as diferenças entre estes e o que deve ser observado pelo investidor no momento da oferta ${ }^{66}$.

\footnotetext{
${ }^{65}$ O CEO da FINMA, Mark Branson, vê essas diretrizes como uma forma de ajudar a tecnologia Blockchain a entrar com sucesso nos mercados suíços, observando que as empresas Blockchain "não podem simplesmente contornar o quadro regulamentar testado". Ele afirma, em comunicado de imprensa sobre as diretrizes que "Nossa abordagem equilibrada para lidar com projetos e inquéritos sobre ICO permite que os inovadores legítimos naveguem no cenário regulatório e assim lançem seus projetos de forma consistente com nossas leis que protegem os investidores e a integridade do sistema financeiro". Para maiores informações, veja ZUCKERMAN, Molly Jane. Autoridade financeira suíça lança diretrizes regulamentares específicas para a ICO. Disponível em $<$ https://br.cointelegraph.com/news/swiss-financial-authority-releases-ico-specific-regulatoryguidelines> Acesso em 06 de nov. de 2018.

66 "FINMA's principles focus on the function and transferability of tokens In assessing ICOs, FINMA will focus on the economic function and purpose of the tokens (i.e. the blockchain-based units) issued by the ICO organiser. The key factors are the underlying purpose of the tokens and whether they are already tradeable or transferable. At present, there is no generally recognised terminology for the classification of tokens either in Switzerland or internationally. FINMA categorises tokens into three types, but hybrid forms are possible: Payment tokens are synonymous with cryptocurrencies and have no further functions or links to other development projects. Tokens may in some cases only develop the necessary functionality and become accepted as a means of payment over a period of time; Utility tokens are tokens which are intended to provide digital access to an application or service; Asset tokens represent assets such as participations in real physical underlyings, companies, or earnings streams, or an entitlement to dividends or interest payments. In terms of their economic function, the tokens are analogous to equities, bonds or derivatives." (Press Release: FINMA publishes ICO guidelines. Disponível em $<$ https://webcache.googleusercontent.com/search?q=cache:TFGUiFPXDqAJ:https://www.finma.c
} 
A partir desta diretriz, a intenção do órgão é impulsionar as discussões sobre o tema resultando na edição de leis específicas para a oferta, deixando claro que continua com a supervisão dos ICO buscando identificar possíveis irregularidades:

As announced in September 2017, FINMA is conducting investigations into a number of cases involving ICOs. If FINMA becomes aware that ICO business models have breached supervisory law, were intended to circumvent regulation, or were fraudulent in their intent, it will launch enforcement proceedings ${ }^{67}$

\subsection{Demais países}

Além dos exemplos citados acima, destaca-se a França, que recentemente aprovou um projeto de ICO proposto pelos reguladores do mercado financeiro francês, a Autorité Des Marchés Financiers (AMF). Atualmente, antes de qualquer emissão de token, a empresa que queira levantar fundos através de um ICO, deverá solicitar uma licença à AMF a partir do envio do White Paper, que deverá conter informações detalhadas sobre a oferta e o emissor. Após a análise, a AMF está habilitada a conceder a licença para a emissão.

A França vem se mostrado otimista com a tecnologia blockchain com edição de novas leis que pretendem melhorar a economia e transformar o país em uma referência europeia no setor. Para tanto, as autoridades francesas mantêm diálogo com empresários interessados em investimentos em criptomoedas, buscando obter uma melhor compreensão do mercado, bem como entender os seus problemas, para regulá-los em conformidade.

A Alemanha, por outro lado, apresentou uma posição mais global sobre criptomoedas em uma perspectiva regulatória. Nesse sentido, já existem especulações sobre possíveis reuniões realizadas entre membros do Parlamento Europeu sobre a regulamentação dos ICOs. O instituto belga

h/en/ /media/finma/dokumente/dokumentencenter/8news/medienmitteilungen/20180216-mm-icowegleitung.pdf\%3Fla\%3Den+\&cd=1\&hl=pt-BR\&ct=clnk\&gl=br>Acesso em 06 de nov. de 2018) ${ }^{67}$ Ibid. p. 3. 
Bruegel também divulgou recentemente um relatório que pedia uma legislação unificada sobre criptomoedas na União Europeia e um exame mais detalhado de como eles eram distribuídos aos investidores.

Pelo exposto acima, resta clara a falta de definição sobre o tema. Entre proibições e diretrizes que buscam uma regulamentação para o tema, a preocupação de todos é manter a vigilância e supervisão em relação a todas as ofertas de ICO realizadas, buscando identificar possíveis irregularidades e, por outro lado, entender as necessidades do mercado e o procedimento esperado para edição de normas eficientes capazes de garantir a proteção dos investidores e fomentar essa nova forma de investimento que tanto cresce. 


\section{CONCLUSÃO}

O presente trabalho teve o objetivo de analisar o procedimento do Initial Coin Offering e a necessidade de regulamentação destas ofertas, uma vez que podem ser configuradas como ofertas de valores mobiliários e, portanto, sujeitas a supervisão da CVM.

Para tanto, analisou-se, no primeiro capítulo, o surgimento das criptomoedas, buscando demonstrar as alterações que esta nova forma de pagamento trouxe ao sistema monetário. Com o fim de identificar sua natureza jurídica, traçou-se uma breve exposição dos conceitos de moeda fiduciária e de moeda digital, buscando compará-las com as criptomoedas, uma vez que estas podem conferir direito de crédito a seus titulares. Em seguida, buscou-se evidenciar suas diversas finalidades, a fim de apresentar o conceito que defende a natureza híbrida das criptomoedas.

O segundo capítulo propõe uma breve explicação sobre o conceito de valores mobiliários. Para tanto, foi apresentado o conceito do Howey Test, conforme definido pelos tribunais norte-americanos, indicando as características necessárias para configuração de um "contrato de investimento" como valor mobiliário. Com esta breve exposição, visou-se demonstrar, a partir da definição de valores mobiliários da legislação brasileira, a possibilidade da configuração das criptomoedas como títulos ou contratos de investimento coletivo.

O procedimento de um ICO e suas características foram analisados no capítulo três. Neste, analisou-se com maior profundidade as diferentes classificações dos tokens objeto de oferta, buscando expor suas principais diferenças e as possíveis consequências jurídicas de cada um.

Com base em casos concretos já analisados tanto pela CVM como pelos tribunais norte-americanos, foi demonstrado neste capítulo como e se uma oferta de utility tokens pode vir a ser classificada. Por fim, antecedendo a análise de ofertas de equity tokens como ofertas de valores mobiliários, o capítulo expôs os motivos pelos quais as ofertas de debt tokens não estão 
sujeitas a supervisão da CVM, uma vez que não são classificadas como ofertas de valores mobiliários.

Por sua vez, o capítulo 4 tratou da análise de ofertas de equity tokens que, devido aos direitos conferidos aos seus titulares, devem ser objeto de registro e supervisão da CVM. Por meio da análise de casos concretos, o capítulo demonstra os pontos de atenção da autarquia na supervisão destas ofertas.

Neste mesmo capítulo, foram apresentadas duas ofertas de valores mobiliários já regulamentadas pela CVM, quais sejam, o IPO e o Equity Crowdfunding. O objetivo deste capítulo é a análise destas regulamentações, buscando incentivar possíveis adaptações nestas para a realização de um ICO ou, alternativamente, partindo destas normas, a criação de uma norma específica capaz de viabilizar a realização destas ofertas garantindo ao investidor a devida proteção necessária.

Por fim, passou-se a analisar, no capítulo 5, a atuação das agências reguladoras de diversos países quanto à realização de ICOs, uma vez que é necessária a análise das regulamentações já existentes buscando embasar as discussões no Brasil.

A partir do presente trabalho, acredito que, ao analisarmos o arcabouço regulatório vigente, o espírito e a dinâmica do ICO me parece em descompasso com a complexidade dos procedimentos indicados pela CVM. Desta forma, entendo ser improdutivo regulamentar uma tecnologia tão inovadora como o ICO nestes moldes.

Com base na análise dos casos concretos, buscando entender as necessidades do mercado e dos desenvolvedores, os órgãos reguladores brasileiros poderão apresentar um novo olhar, de forma a criar uma regulamentação capaz de incentivar esta nova forma de investimento e garantir a proteção necessária ao mercado de capitais. Assim, concluo que, ao analisarmos os diferentes tokens e os contornos de suas ofertas, é evidente que esta será uma tarefa difícil, porém, necessária. 


\section{REFERÊNCIAS BIBLIOGRÁFICAS}

ABRAHÃO, Nelson. Direito Bancário. 16 ed. São Paulo: Saraiva, 2016. 624 p.

BACHA, Carlos José Caetano. Macroeconomia Aplicada à Análise da Economia Brasileira. São Paulo: Editora da Universidade de São Paulo, 2004.

BANCO CENTRAL DO BRASIL. Comunicado no 25.306, de 19 de $\begin{array}{lllll}\text { fevereiro } & \text { de } & \text { Disponível }\end{array}$ <https://www3.bcb.gov.br/normativo/detalharNormativo.do?method=detalh arNormativo\&N=114009277> Acesso em 18 de set. de 2018.

BANCO CENTRAL DO BRASIL. Comunicado $\mathrm{n}^{\circ} 31.379$ de 16 de novembro de $2017 . \quad$ Disponível em $<$ https://www.bcb.gov.br/pre/normativos/busca/normativo.asp?numero=313 79\&tipo=Comunicado\&data=16/11/2017> Acesso em 18 de set. de 2018

BARBOSA, Tatiana Casseb B. M. A Revolução das Moedas Virtuais: Bitcoins e Altcoins. São Paulo: Revoar, 2016. 359 p.

BINNIE, Ricardo; MARTINS, Alessandra Carolina Rossi. Criptomoeda: Considerações Acerca de sua Tutela Jurídica no Direito Internacional e Brasileiro. Revista de Direito Empresarial. São Paulo. v. 11. Set- Out / 2015. p. $195-221$.

CAMPOS, Emília Malgueiro. Criptomoedas e blockchain: o dinheiro no mundo digital. Rio de Janeiro: Lume Juris, 2018. 128 p. 
CARVALHO, Cesar Augusto Rodrigues de. Equity crowdfunding: Regime Jurídico e sua Nova Regulamentação. Revista de Direito Bancário e do Mercado de Capitais. São Paulo. v. 78. Out - Dez / 2017. p. 47 - 76.

COMISSÃO DE VALORES MOBILIÁRIOS - CVM. Deliberação CVM n 785, de 19 de dezembro de 2017. Disponível em <http://www.cvm.gov.br/export/sites/cvm/legislacao/deliberacoes/anexos/0 700/deli785.pdf> Acesso em 28 de set. de 2018.

COMISSÃO DE VALORES MOBILIÁRIOS - CVM. Deliberação CVM n ${ }^{\circ}$ 790, de 28 de fevereiro de 2018. Disponível em < http://www.cvm.gov.br/export/sites/cvm/legislacao/deliberacoes/anexos/0 700/deli790.pdf> Acesso em 28 de set. de 2018.

.COMISSÃO DE VALORES MOBILIÁRIOS - CVM. Processo CVM nº RJ2007/11.593, Registro Col. no 5730/07. Voto do Diretor Marcos Barbosa Pinto. Julgado em: 15 de janeiro de 2008. Disponível em < http://www.cvm.gov.br/export/sites/cvm/decisoes/anexos/0004/5615-0.pdf> Acesso em 09 de out. de 2018.

.COMISSÃO DE VALORES MOBILIÁRIOS - CVM. Processo $n^{\circ}$ 19957.010938/2017-13. Memorando no 19/2017-CVM/SRE. Relator Dov Rawet - Superintendente de Registro de Valores Mobiliários. Emitido em: 27 de dezembro de 2017. Disponível em <http://www.cvm.gov.br/export/sites/cvm/decisoes/anexos/2018/20180130/ 088818_ManifestacaoSRE.pdf> Acesso em 14 de out. de 2018.

.COMISSÃO DE VALORES MOBILIÁRIOS - CVM. Processo n ${ }^{\circ}$ 19957.011454/2017-91. Memorando no 17/2017-CVM/SRE. Relator Dov Rawet - Superintendente de Registro de Valores Mobiliários. Emitido em: 18 
de dezembro de 2017. Disponível em <http://www.cvm.gov.br/export/sites/cvm/decisoes/anexos/2017/20171219/ 0882.pdf> Acesso em 28 de set. de 2018.

COMISSÃO DE VALORES MOBILIÁRIOS - CVM. Processo SEI 19957.010938/2017-13, Reg. $n^{\circ}$ 0888/18. Relator SRE. Julgado em: 30 de janeiro de $2018 . \quad$ Disponível em <http://www.cvm.gov.br/decisoes/2018/20180130_R1.html> Acesso em 14 de out. de 2018.

CONGRESSO DE CIÊNCIAS SOCIAIS APLICADAS RESPONSABILIDADE SOCIAL E CONSUMO SUSTENTÁVEL, 2010, Setor de Ciências Sociais Aplicadas, UNICENTRO. A Evolução da Moeda no Contexto Histórico. 2010. 4 p. Disponível em:

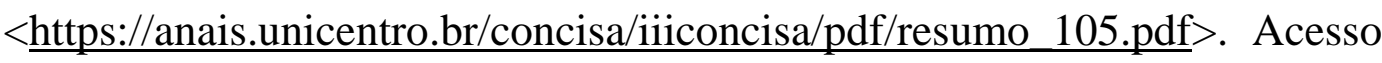
em: 16 set. 2018.

Cryptocurrency ICO Stats 2018. Disponível em

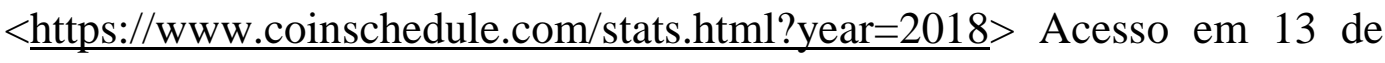
out de 2018.

DINIZ, Maria Helena. Dicionário Jurídico. São Paulo: Saraiva, 1996. 4230 p.

DOURADO, Maurício Custódio. A Sujeição do Initial Coin Offering (ICO) à Regulação do Mercado de Capitais no Brasil. Revista de Direito Bancário e do Mercado de Capitais. São Paulo. v. 79. Jan - Mar / 2018. p. 77 - 98.

EIZIRIK, Nelson et al. Mercado de Capitais - Regime Jurídico. $3^{\text {a }}$ Ed. Rio de Janeiro: Renovar. 2011. 660 p. 
ESTADOS UNIDOS DA AMÉRICA. Securities Act of 1934 - Release N ${ }^{\circ}$ 81207 / July, 25, 2017. Report of Investigation Pursuant to Section 21(a) of the Securities Exchange Act of 1934: The DAO. $<$ https://pt.scribd.com/document/354711758/SEC-

Report\#download\&from_embed> Acesso em 06 de nov. de 2018.

ESTADOS UNIDOS DA AMÉRICA. Securities Act of 1993 - Release No 10445 / December 11, 2017. Administrative Proceeding File. № 3-18304. in the matter of Munchee Inc. Order Instituting Cease-Anddesist Proceedings pursuant to Section 8A of the Securities Act of 1933, Making Findings, and Imposing a Cease-and-Desist Order.. Relator: Brent J. Fields, Secretary.. Disponível em 〈https://www.sec.gov/litigation/admin/2017/33-10445.pdf〉 Acesso em 17 de out. de 2018.

ESTADOS UNIDOS DA AMÉRICA. United States District Court Eastern District of Texas. Memorandum Opinion $n^{\circ}$ Case 4:13-cv-00406-RC-ALM. SECURITIES AND EXCHANGE COMISSION. TRENDON T. SHAVERS and BITCOIN SAVINGS AND TRUST. Relator: Ammos L. Mazzant, United States Magistrate Judge. Eastern District of Texas, TE, 06 de janeiro de 2013. Memorandum Opinion Regarding the Court's Subject Matter Jurisdiction. Disponível em <https://www.sec.gov/litigation/complaints/2013/comp-pr2013-132.pdf> Acesso em 09 de out de 2018.

FILHO, Ary Oswaldo Mattos. O Conceito de Valor Mobiliários. Revista de Administração de Empresas. Rio de Janeiro. Abr - Jun / 1985. Disponível em $\langle$ http://www.scielo.br/pdf/rae/v25n2/v25n2a03 $>$ Acesso em 20 de out. de 2018. 
FOLHAPRESS. Operação para ofertar bitcoins é suspensa. Disponível em $<$ https://www.folhape.com.br/economia/economia/economia/2017/12/21/N WS,52967,10,550,ECONOMIA,2373-OPERACAO-PARA-OFERTARBITCOINS-SUSPENSA.aspx > Acesso em 28 de set. de 2018.

FRANCO, André; BAZAN, Vinicius. Criptomoedas: melhor que dinheiro. São Paulo: Empiricus, 2018.

HUGHES, Eric. A Cypherpunk's Manifesto. 1993. Disponível em $<$ https://www.activism.net/cypherpunk/manifesto.html $>$ Acesso em 15 de set. 2018.

INVESTOPEDIA. Peer-To-Peer (P2P) Lending - What is 'Peer-To-Peer $\begin{array}{llll}\text { Lending } & \text { (P2P). } & \text { Disponível }\end{array}$ $<$ https://www.investopedia.com/terms/p/peer-to-peerlending.asp\#ixzz5WB56KHRJ> Acesso em 16 de set de 2018.

MANCHIONI, Jarbas Andrade. "ICO” e as Criptomoedas: Regime Jurídico e suas Incertezas. Revista de Direito Bancário e do Mercado de Capitais. São Paulo. v. 80. Abr - Jun /2018. p. 15 - 32.

MATTOS FILHO, Ary Oswaldo. Direito dos valores mobiliários. Rio de Janeiro: Editora FGV, 2015. v. 1. t. 2. 404. p.

MENDES, Guilherme. ICO, oferta inicial de moedas virtuais, fomenta discussões jurídicas. Disponível em <https://www.jota.info/tributos-eempresas/mercado/ico-discussao-juridica-17042018> Acesso em 13 de out. de 2018. 
NAKAMOTO, Satoshi. Bitcoin: A Peer-to-Peer Electronic Cash System. Disponível em <https://bitcoin.org/bitcoin.pdf> Acesso em 15 de set. 2018.

O’NEAL, Stephen. Hong Kong Continues Taking Regulatory Action, Hopes to Become International Blockchain Hub. Disponível em $<$ https://cointelegraph.com/news/hong-kong-continues-taking-regulatoryaction-hopes-to-become-international-blockchain-hub> Acesso em 06 de nov. de 2018.

PINHEIRO, Juliano Lima. Mercado de Capitais. $8^{\text {a }}$ Ed. São Paulo: Editora Atlas, 2016. 545 p.

PRESS RELEASE: FINMA publishes ICO guidelines. Disponível em $<$ https://webcache.googleusercontent.com/search?q=cache:TFGUiFPXDqA J:https://www.finma.ch/en/ /media/finma/dokumente/dokumentencenter/8n ews/medienmitteilungen/20180216-mm-icowegleitung.pdf\%3Fla\%3Den $+\& c d=1 \&$ hl=pt-BR\&ct=clnk\&gl=br $>$ Acesso em 06 de nov. de 2018.

RAZA, Ali. Analisando a proibição final da China em todos os sites de criptografia e ICO. Disponível em 〈https://cryptoslate.com/analyzingchinas-ultimate-ban-crypto-ico-websites/> Acesso em 06 de nov de 2018.

ROBBINS, Robert. B; BUDOFSKY, Daniel N. Munchee ICO. Commission's action shows the limited utility of the utility token-security token distinction. Disponível em <https://www.pillsburylaw.com/en/newsand-insights/the-secs-shutdown-of-the-munchee-ico.html> Acesso em 17 de out. de 2018. 
SILVA, Luis Gustavo Doles. Blockchain como Sistema de Custódia de Valores Mobiliários no Âmbito do Mercado de Capitais Brasileiros. Revista de Direito Bancário e do Mercado de Capitais. São Paulo. v. 80. Abr - Jun / 2018. p. $93-106$.

WORLD BANK, infoDev, Finance and Private Sector Development Department. Crowdfunding's Potential for the Developing World. Washington, $\quad$ DC. 2013. Disponível em <http://documents.worldbank.org/curated/pt/409841468327411701/pdf/840 000WP0Box380crowdfunding0study00.pdf> Acesso em 05 de nov. de 2018.

YAZBECK, Otávio. Regulação do mercado financeiro e de capitais. 2 ed. Rio de Janeiro: Elsevier, 2007. 392 p.

ZUCKERMAN, Molly Jane. Autoridade financeira suíça lança diretrizes regulamentares específicas para a ICO. Disponível em <https://br.cointelegraph.com/news/swiss-financial-authority-releases-icospecific-regulatory-guidelines > Acesso em 06 de nov. de 2018. 